Portland State University

PDXScholar

6-5-1973

\title{
Between Words and Actions: the Problem of Motivation in Symbolic Interactionism
}

Robert Scott Broadhead

Portland State University

Follow this and additional works at: https://pdxscholar.library.pdx.edu/open_access_etds

Part of the Social Psychology Commons, and the Sociology Commons Let us know how access to this document benefits you.

\section{Recommended Citation}

Broadhead, Robert Scott, "Between Words and Actions: the Problem of Motivation in Symbolic Interactionism" (1973). Dissertations and Theses. Paper 1961.

https://doi.org/10.15760/etd.1960

This Thesis is brought to you for free and open access. It has been accepted for inclusion in Dissertations and Theses by an authorized administrator of PDXScholar. Please contact us if we can make this document more accessible: pdxscholar@pdx.edu. 
AN ABSTRACT OF THE THESIS OF Robert Scott Broadhead for the Master of Science presented June 5, 1973.

Title: Between Words and Actions: The Problem of Motivation in Symbolic Interactionism

APPROVED BY MEMBERS OF THE THESIS COMMITTEE:

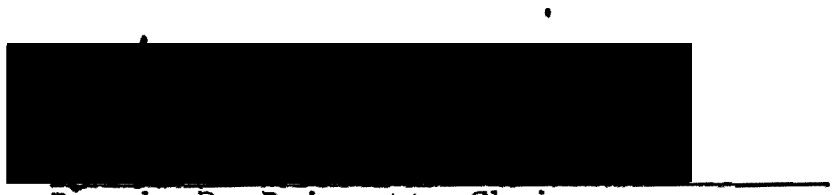

Dennis D. Brissett, Chairman

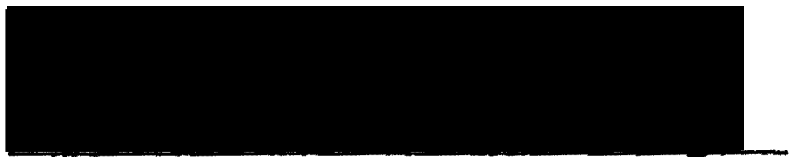

Charles D. Bolton

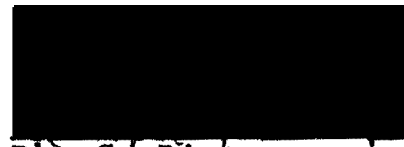

Ray C/ Rist

The development of a theory of motivation in symbolic interactionism is traced, with particular reference to the work of G. H. Mead, Kenneth Burke, C. W: Milis, Nelson Foote, and Ernest Becker. Specific attention is focused on comparing the original theoretical assumptions of particularly Mead and Burke to the varying formulations of the problems of motivation that were later developed by symbolic interactionists. Specifically, it is argued that, primarily due to Burke's analysis, the traditional practice of deterministically explaining human action as being the result of variously imagined motives "in" people is, in fact, 
no explanation at all but simply a variety of metaphorical redescriptions dressed in causal vocabulary. Rather than something "in" people that determines behavior, Burke argued that motives are a particular. kind of communication that people use to rationalize given actions in specific situations.

Following these assumptions, C.W. Mills was later able to integrate Burke's analysis with Mead's (et al.) theory of symbolic interactionism. However, as symbolic interactionism was later developed various theorists reintroduced the deterministic bias into the problem of motivation. A critique of this determinism is developed based on the "fallacy of tautology."

It is finally argued that, as a kind of communication that interactants use, the problem of motivation alludes to a sense of "drama" in social interaction in which individuals negotiate motives in order to influence the behavior of significant others. Thus, motives are seen to derive their meaning problematically in terms of how others respond in social interaction to an individual's avowed motive. 
BETWEEN WORDS AND ACTIONS: THE PROBLEM OF MOTIVATION IN SYMBOLIC INTERACTIONISM

By

ROBERT SCOTT BROADHEAD

A thesis submitted in partial fulfillment of the requirements for the degree of

MASTER OF SCIENCE

in

SOCIOLOGY

Portland State University

1973 
TO THE OFFICE OF GRADUATE STUDIES:

The members of the Committee approve the thesis of

Robert Scott Broadhead presented June 5, 1973.

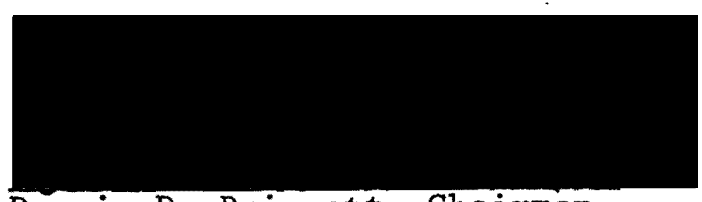

Dennis D. Brissett, Chairman

Charles D. Bolton

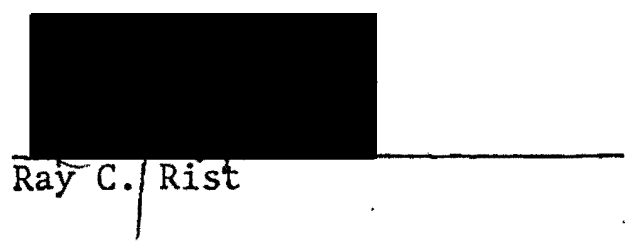

APPROVED :

Don C. Gibbons, Head, Department of Sociology

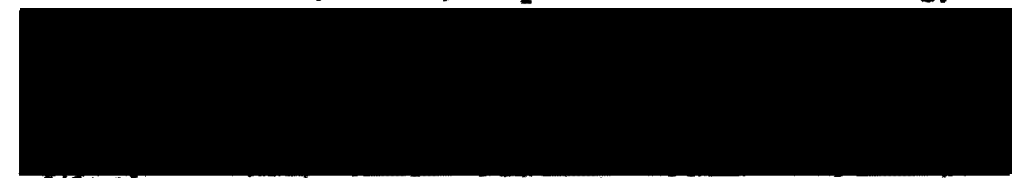

David T. Clark, Dean of Graduate Studies 


\section{ACKNOWLEDGEMENTS}

Many thanks to my Thesis Committee for offering me an enduring and inspiring relationship, and many hours of scholarly debate. Dennis Brissett made two trips to Portland from Minnesota for consultation. Charles Bolton, even while confined to bed, developed several lengthy critiques of the thesis that were extremely insightful and challenging. Ray Rist provided a source of inspiration for graduate study that was aggressive and unendingly socially relevant.

Thanks to Roslyn MacDonald for the excellent typing.

I am indebted to all of the sociology staff at Portland State University, and several graduate students, for the generosity they have shown me, the understanding, and the friendship. 
TABLE OF CONTENTS

PAGE

ACKNOWLEDGEMENTS. . . . . . . . . . . . . . . . . . . . $i i i$

CHAPTER

I INTRODUCTION. . . . . . . . . . . . . . 1

Thesis Format ................. 3

II G. H. MEAD'S ANALYSIS OF MEANING. . . . . . . . . 7

"Minded Behavior" ............... 9

Action. . . . . . . . . . . . . 16

III KENNETH BURKE AND THE PROBLEM OF MOTIVES. . . . . . . . . 19

Perspective by Incongruity. . . . . . . . . 24

IV AN EXCURSIS ON CAUSE AND DETERMINISM IN SYMBOLIC

INTERACTIONISM: R. S. PETERS . . . . . . . . . . . 28

A Critique of Cause and Determinism....... 30

Determinism in Symbolic Interactionism. . . . . . 33

The Concept of Emergence............. 40

Brief Summary .............. . . 44 44

$\mathrm{V}$. C. WRIGHT MILLS' SOCIOLOGICAL IMAGINATION . . . . . . 46

Consequential Situations and Surrogates for

Action. ................ 46

VI NELSON FOOTE ON IDENTIFICATION. . . . . . . . . . 51

A Supplement to Role Theory . . . . . . . . . 54

The Hiatus. . . . . . . . . . . . . 56 
CHAPTER

VII ERNEST BECKER'S CRITIQUE OF MILLS . . . . . . . . . . . . 58

The Hiatus, Par Excellence. . . . . . . . . . 60

The Hiatus as Everyone's Problem. . . . . . ... 62

VIII - MOTIVES AS DRAMATURGICAL PROBLEMS . . . . . . . . . . 64

Stigma as Everyone's Problem........... 66

Motives as Problems Involving Consequences. . . . . 67

The Sociology of Motivation : . . . . . . . 70

IX CONCLUSION. . . . . . . . . . . . . . . 73

NOTES . . . . . . . . . . . . . . . . . . . 75

REFERENCES. . . . . . . . . . . . . . . . . . . . 81 


\section{CHAPTER I}

\section{INTRODUCTION}

The first formulation of a theory of motivation that was amenable to a truily sociological perspective was developed in 1932, not by a sociologist, but a literary critic and poet, Kenneth Burke. This work was published in 1935. A year prior to this a collection of lectures was assembled that had been delivered by a professor at the University of Chicago, George H. Mead. Mead's work represented a pivotal development of a sociological psychology concerning the nature of "mind," "self," and "society," called symbolic interactionism. ${ }^{1}$ This is not to say that Mead was alone in this endeavor for indeed, John Dewey, William James, Charles Cooley, and James M. Baldwin, among others, also participated. But Mead's collection of lectures represented a major, if not the major effort in the development of symbolic interactionism. Moreover, it was Mead's collection of lectures that was later employed as representing the basis of symbolic interactionism, and that eventually was wedded to Burke's work on motivation.

But this did not happen until 1940. Interestingly enough, two major papers were published in 1940 both dealing with the problem of motivation in sociology. One was published in the American Journal of Sociology by Robert MacIver (1940), then at Columbia, entitled "The Imputation of Motives." The other paper was written at the University of Wisconsin by C. Wright Mills, then a doctoral candidate, entitled "Situated Actions and Vocabulary of Motives." This was published in a rival journal, The 
American Sociological Review.

Sociologically speaking, MacIver's paper represented the traditional confusion and misunderstanding in the discipline toward the problem of motives. Basically, the notion of "motive" and "cause" was still confounded; motives were assumed to involve internal forces or determinants of behavior. MacIver (1940:1-2), however, was sensitive to the fact that "The peculiar feature of the imputation of motives is that we are asserting a nexus between an overt action and a purely subjective factor that cannot be exposed to any kind of direct scrutiny and that is not, as such, manifest in the action." But in spite of this embarrassment, MacIver encouraged sociologists not to give up on the notion of motive. He concluded by urging further investigation on

the impulses generating social movements of all kinds, the sentiments that characterize the various forms of group solidarity, the foci of emotional attachments under different social conditions. . . There is a sociology of emotion that is almost entirely unexplored and that might throw much light on the problem of motivation (MacIver, 1940:11-12).

Theoretically, C. Wright Mills appeared to settle this whole problem between "cause" and "motives" by integrating Burke with Mead. By recognizing that motives are a special type of "Iingual vocabulary," and that language, "rather than expressing something which is prior and in the person . . . is taken by other persons as an indicator of future actions" (Mills, 1962:439), Mills developed a truly sociological theory of motives. Put simply:

Rather than fixed elements "in" an individual, motives are the terms with which interpretation of conduct by social actors proceeds. This imputation and avowal of motives by actors are social phenomena to be explained. . . Motives are names for consequential situations, and surrogates for actions leading to them (Mills, 1940:439-40) (emphasis in the original). 
I mentioned above that Mills' 1940 paper settled the issue between "causes" and "motives"; actually that is an over-statement. Although currently the issue is probably settled for most practicing sociologists, the controversy is still raging in other social science disciplines, particularly psychology. ${ }^{2}$ It was not until as late as 1958 that a very well received work by R. S. Peters (1958) grappled with the distinction between cause and motive from a grammatical and logical point of view, and hopefully settled the issue in philosophy.

\section{THESIS FORMAT}

Since 1940, a number of theorists have continued to develop the problem of motivation within the larger development of symbolic interactionism. However, as symbolic interactionism has evolved into a number of different sub-types [Kuhn (1967) counts seven], so too, the problem of motivation has conceptually splintered. At present the literature on motivation is frequently confusing and ambiguous due to difference between the various sub-types of symbolic interactionism. For instance, some theorists speak of motives as a "special type of communicative conduct," while others refer to motives as words. Some refer to motives as properties of situations; other theorists speak of them as properties of social structures. In one sub-theory, motives are said to enter into action only occasionally, while in another, action is always institutionally and historically linked. With these difficulties in mind, the purpose of this thesis is to delineate the development of the problem of motivation in the history of symbolic interactionism. The effort is considered warranted on the following counts:

1. such a study has not yet been made; 
2. the literature in the sociology of motivation in symbolic interactionism is frequently confusing and ambiguous due to the differences between the various sub-types of the theory;

3. the sociology of motivation itself is still a recent and emerging field that can yet profit from greater attention;

4. the problem of motivation is squarely situated in addressing one of the major problems of sociology in genera1-"what is the nature of social action?"

The analysis will proceed along the following format. First, the . works of James M. Baldwin, William James, and in particular George H. Mead will be analyzed to establish the original theoretical assumptions of symbolic interactionism with special reference to the nature of "meaning," "action" and "minded behavior." Secondly, Kenneth Burke's (1954) Permanence and Change will be analyzed. since it was basically this: treatise that $C$. Wright Mills integrated with symbolic interactionism. Thirdly, the problem of motivation will then be traced as it was later developed within symbolic interactionism. Lastly, specific attention will be focused on comparing the original theoretical assumptions of particularly Mead and Burke to the varying formulations of the problem of motivation that were later developed by symbolic interactionists; this comparison will afford the basis of critique of this later development. Specifically, it will be shown that, primarily due to the impact of Burke's analysis, the traditional practice of deterministically explaining human action as being the result of variously imagined motives "in" people is, in fact, no explanation at all but simply a variety of metaphorical redescriptions dressed in causal vocabulary. Rather than something "in" people that determines behavior, Burke argued that motives are a particular kind of communication that people use to rationalize given actions in specific situations. In terms of explaining action, therefore, the deterministic bias drops out of the explanation entirely, and the 
meaning of motives then becomes understood as a general problem of communication in social interaction generally.

Following these assumptions, C. W. Mills was later able to integrate Burke's analysis with Mead's (et al.) theory of symbolic interactionism, which is, par excellence, an understanding of action based on symbolic communication. However, it will be argued that, as symbolic interactionism was later developed, various theorists, including Mills, ironically, reintroduced the deterministic bias into the problem of motivation. Rather than deriving their meaning from on-going social interaction, motives came to be seen still as features of communication to be sure, but as a particular kind of communication that, in various ways "induce," "control," and determine action in general. Specifically, rather than derive their meaning from on-going social interaction, motives came to be understood as certain kinds of "forces" in communication that in some way gave meaning and control to interaction. Mead's emphasis that meaning is derived and built up through on-going interaction is therefore shifted from a position of primary importance to a position of dependency on those "forces" imagined to give meaning to interaction.

The underlying thesis of this essay is that the meaning of all communication in general, including motives as one type of communicative conduct, is created and sustained through on-going social interaction. Moreover, because interaction is fundamentally problematic, the meaning of communicative behavior, including motives, is also variable and problematic. Thus, it is argued, to suggest that meaning is given to interaction by motives, rather than derive their meaning from interaction itself, is fundamentally a contradiction to the basic assumptions of symbolic interactionism. Moreover, it is also argued, that to explain 
the meaning of interaction as being the result of anything other than on-going interaction itself is fundamentally tautological. The tautology goes as follows. The meaning of a given behavior or interaction is used as evidence of another phenomenon or object which can be arbitrarily envisioned--norms, roles, selves, or motives. This object is conceptualized as an independent variable which the original interaction is then argued to derive or be dependent on for its meaning. But because, in this line of reasoning, the dependent variable (meaningful action) ${ }^{3}$. is used both as evidence of the independent variable and then explained by that variable, the argument is fundamentally circular and thus has no explanatory value.

Finally, it will be argued that motives should be understood as. terms of interpretation that individuals use to rationalize questioned behavior. The problem of motivation, in this sense, alludes to a sense of "drama" in social interaction in which individuals negotiate motives in order to influence the behavior of significant others. Thus, motives are seen to derive their meaning problematically in terms of how others respond in social interaction to an individual's motive avowal. From this standpoint, the role of a sociologist as an observer of social phenomena, is to describe the various techniques that interactants employ in negotiating their situated interactions. It will be argued that, dramatistically, the imputation and avowal of motives is one such technique that the sociologist should attempt to describe and understand. 
CHAPTER II

\section{G. H. MEAD'S ANALYSIS OF MEANING}

The applicability of early symbolic interactionism to a sociological theory of motivation was not in terms of what it had to say about motivation but rather, in terms of what it had to say about meaning. The reason for this is that Mead, along with William James and James Baldwin, was arguing that the meaning of human behavior was socially constituted, and thus it could not be ascertained by looking either "behind" or "within" the organism for underlying reasons such as instincts, drives, or emotions. For instance, in 1892 James argued that the "self" of the human organism, or that which man calls "me," is a socially predicated value.

In its widest possible sense, however, a man's Me is the sum total of all that he can call his, not only his body, and his psychic powers, but his clothes and his house, his wife and children, his ancestors and friends, his reputation and works, his lands and horses, and yacht and bank-account (James, 1968:41).

In the same sense, Baldwin argued in 1897 that the meaning of thought itself was not to be discovered in purging the organism in an endeavor to find "reactive expressions" or "motor attitudes." Baldwin (1968:62) argued, "My thought of self is in the main, as to its character as a personal self, filled up with my thought of Others, distributed variously as individuals . . " Baldwin (1968:165) even expanded this sociological sense of meaning to analyze the development of the child:

But see, in this more subtle give-and-take of elements for the building up of the social sense, how inextricably interwoven the ego and the alter really are! The development of the child's 
personality could not go on at all without the constant modification of his sense of himself by suggestion of others. So he himself, at every stage, is really in part some one else, even in his own thought of himself. And then the attempt to get the alter stript from elements contributed directly from his present thought of himself is equally futile. He thinks of the other, the alter, as his socius, just as he thinks of himself as the other's socius: and the only thing that remains more or less stable, through-out the whole growth, is the fact that there is a growing sense of self which includes both terms, the ego and the alter.

In short, the real self is a bipolar self, the social self, the socius (emphasis in the original).

Again, the applicability of early symbolic interactionism to a theory of motivation was in its rejection of the notion that the meaning of human behavior could be found in these dated notions of motives or instincts that, in effect, reduced the significance of behavior to a nonsocial plane. Rather, the meaning of the organism was seen to be socially constituted. It was in this framework that Mead, in particular, came to develop a theory of "mind," "action" and "self" within a sociological reference.

Mead examines this problem through an analysis of the meaning of a gesture. "The term 'gesture' may be identified with these beginnings of social acts which are stimuli for the response of other forms" (Mead, 1934:43). In this sense gestures, including symbols, become meaningful when "they implicitly arouse in an individual making them the same responses which they explicitly arouse, or are supposed to arouse, in other individuals, the individuals to whom they are addressed" (Mead, 1934:47). Thus,

meaning is . . not to be concerned, fundamentally, as a state of consciousness, or as a set of organized relations existing. or subsisting mentally outside the field of experience into which they enter; on the contrary, it should be concerned objectively, as having its existence entirely within the field itself. The response of one organism to the gesture of another in any given social act is the meaning of that gesture... (Mead, 1934:78). 
It is important to note Mead's emphasis here on the role of "response" in the construction of meaning. Meaning is argued to exist objectively within the field of experience only on the basis of the reciprocity of response of others to the gestures within a social act. In thị sense, meaning is contingent upon' a "three-fold relation" within the social act:

this relation of the gesture of one organism to the adjustive response of another organism (also implicated in the given act), and to the completion of the given act--a relation such that the second organism responds to the gesture of the first as indicating or referring to the completion of the given act (Mead, 1934: 76-7) (emphasis in the origina1).

It goes without saying, therefore, that if meaning can be said to exist objectively on the basis of the reciprocity of behavioral responses, the absence of those responses implies that the interaction either comes into question or must await future responses for the consummation of its meaning. And furthermore, meaning can not be said to exist if the response of others within the given act is withheld or is of a nature different than the prescriptions implied in the initiating response. This is merely to recognize that meaning is problematic and variable; it is contingent on the adjustive responses of the other organisms within the act. ${ }^{4}$

\section{I. "MINDED BEHAVIOR"}

Not only did Mead explicate the problem of meaning into a total, social-behavioral point of view, he also expanded the issue into exploring what is meant by the notion, "mind." Since meaning was now seen as an objective, behavioral phenomenon, and not reducible to the "conscious" states of the organism, or some other level, it was logical that Mead 
also explicate the meaning of "mind" in behavioral terms. In doing so, Mead again not only returned to draw off some of the basic arguments of James and Baldwin; he expanded these concepts, especially the notion of "me," into a theory of mind. Parenthetically, it should also be noted that this expansion of James' notion of "me" represents Mead's most significant contribution to symbolic interactionism (see Bolton, 1971).

As noted above, James and Baldwin depicted the "me" in the experience of the organism as viewing self as a social object. Mead (1934:38) recognized this when he stated:

The individual experiences himself as such, not directly, but only indirectly, from the particular standpoints of other individual members of the same social group, or from the generalized standpoint of the social group as a whole to which he belongs.

But Mead makes a brilliant move further. Through the human organism's ability to use language, and therefore symbolize the gestures of a given social act, the individual is able to "import" the conversation of social gestures and therefore symbolically elaborate the organized set of responses that others hold toward him. In other words, through man's symbolic capacity, an individual can "take over" the attitudes or responses of others, hold them symbolically before him, as it were, and thereby selectively respond to them. This is what is meant by the ability of "taking the role of the other." The organized sets of attitudes of the community that one internalizes therefore represent one aspect of the "me" and is called the "generalized other." Put succinctly, Mead (1934:186) says:

I have been presenting the self and the mind in terms of a social process, as the importation of the conversation of gestures into the conduct of the individual organism, so that the individual organism takes these organized attitudes of the others called out by its own attitude, in the form of its gestures, and in reacting to that response calls out other organized attitudes in the com- 
munity to which the individual belongs. This process can be characterized in a certain sense in terms of the " $I$ " and the "Me", the "Me" being that group of organized attitudes to which the individual responds as an "I".

Mind is therefore an on-going communicative behavior that parallels the experience of communication, say, between two people except that it is internalized within the actor. As in the case of two people, where one individual initiates communication through avowal of a gesture, and meaning then becomes established in terms of the other's adjustive response, so too with minded behavior. The "me" represents the organized attitudes of the community; the "I" represents the response to those attitudes. Mind is therefore "the individual importation of the social process" (Mead, 1934:34).

Perhaps Mead's interpretation of "minded behavior" can best be exemplified by an analysis of what is meant by "intention." Due to the ability of symbolically objectifying the response of one's self and others, an individual can organize an "intended" line of action within a situation. Intentions, in this sense, are activities of symbolically elaborating actions of a directed sort that the individual can anticipate carrying out and thereby selectively respond to. Intentions per se can therefore be said to be aspects of an individual's "me"; that is, an objectification of how one expects one's self to respond toward a given goal.

The fact should be underscored, though, that as an activity, intentions are not a constant phenomenon "in" individuals. Like all other activities, "intending" can be engaged in or not. This is merely to note that not all behavior is intentional. For instance, both Mead and his contemporary Dewey (1930) recognized that a considerable portion of action is habitual and carried out without intentional deliberation. 
Moreover, in the process of carefully intending a particular behavior, a whole host of other actions that the individual may be performing cojointly are carried out without conscious control.

Thus it is argued that "intending" is one kind or aspect of minded behavior. And like minded behavior, the meaning of an individual's actions is not something that resides "in" the individual; it becomes established on the basis of action itself. In this respect, the meaning of an intention is not given in and of the intention itself. The meaning of an individual's intention. is given by the individual's response to it. Thus if actions are of a nature different than what was intended, the significance of the original intention is either meaningless or highly ambiguous. The point is, as Mead argued, meaning is an on-going product of response and not a state of mind or consciousness (cf. Mead, 1934: $80-1$ ). And because responses or actions can be variable, the meaning of "mind" and "intention" is also problematic.

Another example that can illustrate Mead's theory of mind is that of "attitude." Although Mead defends the position that meaning is an objective, behavioral phenomenon, he was very much opposed to the extreme position of Watsonian behaviorism. The latter position assumed that because only overt behavior could be scientifically observed and analyzed, covert processes such as "mind," or "consciousness," could therefore be either ignored or denied to exist. Mead (1934:6), on the other hand, argued that "There is a field within the act itself which is not external, but which belongs to the act." Mead is of course referring to the field of consciousness and attitudinal behavior. For instance, Mead (1934:24) argued: 
We approach the distant stimulus with the manipulatory processes already excited. We are ready to grasp the hammer before we reach it, and the attitude of manipulatory response directs the approach. What we are going to do determines the line of approach and in some sense its manner.

By attitude, Mead refers to "the beginnings of social acts,".or incipient acts. As argued above, through the individual's ability to symbolically objectify anticipated actions of others and one's self, one can prepare future actions and attempt to guide behavior accordingly. This is not to argue, however, that the beginning stages of a social act determine the meaning of the consummated act, for as has been argued, the meaning develops as the action itself evolves. In this respect, Mead compares attitudinal behavior with hypothetical behavior, or behavior consisting of the arousal of the individual toward a given action with an imagined or hypothesized consummation of the action. For instance, Mead (1938:25) suggests, "Such an aroused future act has always a hypothetical character. It is not until this initiated response is carried out that its reality is assured." Obviously Mead is reemphasizing the problematics of action itself, and the constructional nature of meaning in action, and not before it. In this sense, an attitude or hypothesis is there as a promise; "it becomes true when it fulfills its promise" (Mead, 1938:103).

It is important to note that Mead's theory conceptualizes mind as a dynamic process as opposed to a "condition" or a "state." As discussed above, the meaning of behavior is not something that resides "in behavior," or "behind" it; behavioral meaning becomes established in terms of the response of one organism to the gesture of the other (or the organism's response to itself). In this same respect, it is the behavioral response of the "I" to the organized sets of attitudes of the "Me" that establishes 
meaning between the two. Meaning is an objective, behavipral development based on response. Now just as the meaning between two individuals is problematic and variable, being contingent on the nature of the response of the other, so too, the meaning of minded behavior is contingent on the response of the "I" toward the "Me." Meaning is not a given, but must be understood processually as an on-goingly established product of response and action. Indeed, Mead is very careful and explicit in making this point. Just as the response of the other person is somewhat uncertain in, say, dialogue, so too the response of the "I" toward the "Me" is problematic. Mead (1934:176) explains it in this way:

I want to call attention particularly to the fact that this response of the "I" is something that is more or less uncertain. The attitudes of others which one assumes as affecting his own conduct constitutes the "me", and that is something that is there, but the response to it is as yet not given. When one sits down to think anything out, he has certain data that are there. Suppose that is a social situation which he has to straighten out. He sees himself from the point of view of one individual or another in the group. These individuals, related all together, give him a certain sense of self. Well, what is he going to do? He does not know and nobody else knows.

Stated somewhat more succinctly, Mead (1934:178) elaborates:

The "me" represents a definite organization of the community there in our own attitudes, and calling for a response, but the response that takes place is something that just happens. There is no certainty in regard to it. There is a moral necessity but no mechanical necessity for the act (emphasis added).

Mead is arguing an important point here. Namely, there is no form of determinism, mechanical or otherwise, that the "me" holds over the "I." The "I," as a response of the organism, is always somewhat uncertain. Now some symbolic.interactionists have reacted to Mead's notion of the "I" claiming that it is "vague," "mystical," and involving a "mysterious biology." None of these claims are warranted. Mead is simply paying cognizance to an undeniable, empirical fact concerning human response: 
men bungle--constantly. Even when all of the facts of any situation are known, as in a well-rehearsed play, mistakes in acting are still made. There is nothing vague about this. For instance, Mead notes the baseball game where one individual is called upon to make a long pitch.

Now, it is the presence of those organized sets of attitudes that constitutes the "me" to which he as an "I" is responding. But what that response will be he does not know and nobody else knows. Perhaps he will make a brilliant play or an error. The response to that situation as it appears in his immediate experience is uncertain, and it is that which constitutes the "I." (Mead, 1934:175).

Mead maintained constant recognition of the fact that meaning is problematic since it is processually contingent on the uncertain responses of others, and the uncertain responses of one's self. Mead's classic example of this is the absent-minded college professor who started to dress for dinner and found himself in his pajamas in bed:

A certain process of undressing was started and carried out mechanically; he did not recognize the meaning of what he was doing. He intended to go to dinner and found he had gone to bed. The . meaning in his action was not present. The steps in this case were all intelligent steps which controlled his conduct with reference to later action, but he did not think about what he was doing. The later action was not a stimulus to his response, but just carried itself out when it was once started (Mead, 1934: 72).

The significance of Mead's argument can be summarized in one statement: there is a hiatus between words, thoughts, and actions. The relationship between that "I" as responsive actions, and the "me" as the organized collection of attitudes and symbols that the "I" responds to, is not direct. There is a gap. The problem of this hiatus will come up again in an analysis of Nelson Foote (1951) and E. Becker (1962a; 1964b). But Mead's recognition of this hiatus is undeniable. He continuously argued that the "I" and the "Me" 
are separated in the process but they belong together in the sense of being parts of a whole. They are separated and yet they belong together. The separation of the "I" and the "Me". is not fictitious. They are not identical, for, as I have said, the "I" is something that is never entirely calculable. The "Me" does call for a certain sort of an "I" in so far as we meet the obligations that are given in conduct itself, but the "I" is always something different from what the situation itself calls for (Mead, 1934:178).

\section{ACTION}

Mead's account of the uncertainty of behavior has been criticized by some as being vague and unexplainable. Again, this is not the case. Mead does provide an explanation and it is centrally involved in his processual theory of meaning. Meaning is based on response, and therefore, in interactional terms, it is created during the course of, and on the basis of, action. Meaning is not inherent in the interactants, say, or before the interaction; it develops during the interaction on the basis of reciprocal action itself. Or, with the individual, meaning does not exist within him, but it develops on the basis of his responses to the organized sets of attitudes or objects that he is singling out. With this understanding, an explanation for the uncertainty of action is forthcoming, and Mead provides it.

It is only as we act that we become aware of the meaning of our actions. As Mead (1934:175-7) says.

The "I" is his action over against the social situation within his own conduct, and it gets into his experience only after he has carried out the act. Then he is aware of it... . The response enters into his own experience only when it takes place.

Put another way, "There again I cannot turn around quick enough to catch myself" (Mead, 1934:174). In this sense, what we frequently believe to be the meaning of our actions takes place largely as memory images. 
As action flows, the meaning can be symbolically objectified, as it were, but until the action is largely over, there is only speculation. Making an object of the meaning of our actions, therefore, is always somewhat delayed and after the fact. This is because of the processual nature of meaning being contingent on responses, not before responses:

It is only after we have said the word we are saying that we recognize ourselves as the person that said it, as this particular self that says this particular thing; it is only after we have done the thing that we are going to do that we are aware of what we are doing. However carefully we plan the future it always is different from that which we can previse, and this something that we are continually bringing in and adding to is what we identify with the self that comes into the level of our experience only in the completion of the act (Mead, 1934:203) (emphasis added).

Thus we see that one's actions can never be fully controlled because they are not totally comprehended during action itself. This is because the meaning of our actions requires the response of the "I" before it can be said to behaviorally exist. And thus, it is because of this peculiar position that the "I" is in that makes the comprehension and control of our actions problematic. "It is because of the "I" that we say that we are never fully aware of what we are, that we surprise ourselves by our own actions" (Mead, 1934:174).

This brings us back to the hiatus between words and actions that Mead depicts so poignantly. It is because of this hiatus and the elusive nature of behavioral meaning that makes the comprehension of one's actions by and large a product of memory. As Mead (1934:176) said, "And when the response takes place, then it appears in the field of experience largely as a memory image. . . We are doing something, but to look back and see what we are doing involves getting memory images." As such, action and meaning must be understood as on-goingly problematic, and the potentiality of discrepancies, errors, and blunders in action is always a latent 
possibility. It is, in fact, around these issues that the problem of motivation became introduced to symbolic interactionism. For the sociological significance of motives is not that they "cause" behavior, but they "justify" or rationalize its discrepancies in social interaction. 


\section{CHAPTER III}

KENNETH BURKE AND THE PROBLEM OF MOTIVES

Mead clearly detailed the symbolic foundation of men's actions; their meaning is to be found within the symbolic interaction of gestures and reciprocating responses. Moreover, this same social process is integral to the behavior of the individual. Specifically, by "internalizing" the conversation of social gestures and thereby symbolically elaborating the organized sets of responses that others hold toward him, the individual can act in terms of anticipated meanings or responses from others. This, however, does not imply that those anticipated responses will occur, but that more than likely they will. It is thus in terms of the "generalized other" that the individual also possesses a personal sense of "self," or a knowledge of how one can expect others to act toward him.

Burke adheres to this same understanding. In any given situation men act in terms of "orientations," which amount to a given set of anticipations (expectations) of how the environment (including others) will respond toward them. As Burke (1954:18) says, people act in terms of

a sense of relationships, developed by the contingencies of experience; this sense of relationships is our orientation; our orientation largely involves matters of expectancy, and affects our choice of means with reference to the future..'

Thus Burke (1954:18) argues that all men are critics especially in the sense that "man attempts to extend the range of his responses and increase their accuracy by deliberately verbalizing the entire field or orientation 
and intexpretation."

Burke also underscores the fact that, while the "generalized other" or one's orientation provides a sense of expectancy toward one's environment, this does not imply that responses actually coincide. As Burke (1954:6-7) suggests,

Orientations can go wrong. . . Thus it will be seen that the devices by which we arrive at a correct orientation may be quite the same as those involved in an incorrect one. We can only say that a given objective event derives its character for us from past experiences having to do with like or related events.

Burke (1954:111) also notes that "we are all necessarily involved in the momentous discrepancies of our present order."

In spite of the problematic, however, Burke argues along with Mead that individuals attempt cognitively to erect a conception of our "self" and our world as coherent and approachable. Burke (1954:74) terms'this tendency as "piety"; ". . . piety is a system-builder, a desire to round things out, to fit experiences together into a unified whole. Piety is the sense of what properly goes with what" (emphasis in the original).

Thus piety is the tendency, as noted above, of the individual deliberately verbalizing the "entire field of orientation" and interpretation. Burke (1954:75) carries this notion of piety even further:

I would even go further in trying to establish this notion of piety as a response which extends through all the texture of our lives but has been concealed from us because we think we are so thoroughly without religion and think that the "pious process" is confined to the sphere of churchliness.

It is within the notions of "orientations" and "piety" that Burke introduces the problem of motivation. Motives are subdivisions of orientations, especially with reference to the orientation one has within specific or co-joined situations. Specifically, motives are "terms of interpretation" or rationalizations that are used by the individual to 
explain his conduct with respect to his orientation in a given situation. As Burke (1954:18) says,

in the human sphere, the subject of expectancy and the judgement as to what is proper in conduct is largely bound up with the subject of motives, for if. we know why people do as they do, we feel that we know what to expect of them and of ourselves. . (emphasis in the original).

As such, motives are rationalizations of one's conduct within given situations with reference to the individual's orientation.

The question then becomes, to what to motives refer? As being aspects of orientations; motives refer to or represent "short-hand" terms for orientations within situations. For instance, Burke (1954:31) gives the following example:

A man informs us he "glanced back in suspicion." Thus suspicion. was his motivation. But suspicion is a word for designating a complex set of signs, meanings, or stimuli not wholly in consonance with one another. . . . By the word "suspicion" he was referring to the situation itself--and he would invariably pronounce himself motivated by suspicion whenever a similar pattern of stimuli recurred.

When avowed, motives therefore rationalize conduct by referring to the contingencies of a given situation, as these contingencies are interpreted via one's orientation. They function to rationalize by conveying to significant others one's interpretation of the contingencies within a situation. Burke notes that when one is asked why he closed the window, the motive-rationalization most conveniently used refers to the contingencies inherent in the situation: "because the room is cold." As such, a motive amounts to nothing more than a rationalistic interpretation of a situation.

This understanding should lend a distinction between an individual's intentions and his motives. Typically the two are believed to be one and the same. However, as was explained above, intentions represent a 
subjectively felt sense of direction within an individual, assuming, of course, that the individual is in fact "intending." Ass an activity, intentions involve symbolically objectifying what one will do in a particular situation with respect to a given goal. But "intending" a particular goal does not automatically insure successful action toward the goal. Indeed, whether or not the intention is meaningful is determined by the nature of the responses to it. Naturally there is, at least potentially, a slip between what one intends and what one does. There are instances where actions do not achieve their goal, or even do not appear to be goal oriented. It is commonly in such cases that "questions" arise by significant others requesting an explanation for the observed conduct. It is in such instances that motive-justifications are introduced. As rationalizations, avowed motives act to explain the individual's orientation within a given situation and thereby justify to the significant audience involved the questioned conduct. In this sense, avowed motives attempt to normalize the conduct of the situated actors (see p. 65). But note that the crucial variable involved in whether a motive justification is accepted is not whether the avowed motive is the same as the individual's intentions (assuming, again, that the person is indeed intending), but rather whether the rationalization satisfies the expectations of the social audience. The emphasis here is on whether the audience accepts the motive, and not on a congruence between what an individual intends (if he intends anything) and what he avows. Indeed, it may be the case that the individual's intentions are altogether different than his avowed motives. But this is exactly the distinction between motives and intentions. Motives are used to justify behavior to social audiences by appealing to the contingencies in situations. But one can 
not explain an individual's intentions on the basis of his rationalization. For instance, an avowed motive may be used to pacify a questioning audience, and yet at the same time obfuscate the individual's actual intentions. Or, an avowed motive may be employed to rationalize a given behavior that was not itself intended but yet called into question by others.

Thus motives and intentions must be understood as altogether different phenomena. The latter problem is a subjectively felt sense of direction that the individual may or may not possess. A motive is strictly a feature of inter-personal communication in general. As a lingual term, a motive functions to justify questioned conduct to significant others. But on the basis of a rationalization of conduct one can not determine an individual!s intention. This is not to suggest that in everyday conduct significant others do not infer intentions from avowed motives. But then it is not uncommon for significant others to be shocked at a later date to discover that one's avowed motives were not one's intentions.

As opposed to the traditional notions of ulterior causes or forces acting within the individual such as drives or even intentions, motives are terms of communication or interpretation that rationalize one's conduct if or when it becomes questioned by others.

Any given situation derives its character from the entire framework of interpretation by which we judge it. And differences in our ways of sizing up an objective situation are expressed subjectively as differences in our assignment of motive (Burke, 1954: 35).

The function of motives therefore should become quite obvious. While through acts of piety individuals may attempt verbally or cognitatively to build coherent and all-embracing orientations toward the world, 
surprises, accidents, and discrepancies constantly threaten their very foundation. Motives, as rationalizations for actions, function interpretatively to bridge the gap between what others expect and what happens.

\section{PERSPECTIVE BY INCONGRUITY}

If motives are merely rationalizations, what then lies deeper that can explain the reasons for an individual's behavior? This is the question of both the skeptic and the scientist. Burke's answer is that the only "reasons" that can be further specified as explaining the behavior of the individual are simply more interpretations or rationalizations. The basis of man's behavior is symbolic interpretation within interaction of other's and one's environment. What is one man's motive therefore can be interpreted by another man as merely his rationalization. But what can be inferred to lie deeper amounts to nothing more than another interpretation or rationalization.

Burke calls the reinterpretation or translation of another man's motives a "perspective by incongruity." This merely involves ignoring the rationalization or motives offered by an individual and interpreting his behavior within a context wholly incongruent with the individual's context. Perspective by incongruity is usually accomplished through. either metaphor, analogy, or law-like generalizations. In this respect the relatively modern philosophic stance of positivistic science is by and large based on perspective by incongruity, just as ancient mystics. As Burke (1954:222) explains:

The identity between motives and situations should suggest why the modern science of statistics tend to turn up conclusions of a strongly mystical cast. By examining a multitude of situations, individually distinct, the scientist attempts statistically to extract a generalization common to all. The mystic 
makes somewhat the same attempt by looking within and naming as the ultimate motive a quality of experience common to all.

This is not to infer, however, that Burke is unaware of the possible value of perspective by incongruity. Indeed, he rècognizes that, whether it be the ancient shaman, witch-doctor, or the modern psychoanalyst, psychologist, or psychiatrist--substitution of a given motive and the bestowal on the individual of a new vocabulary of motives can have pronounced effects, either therapeutically or detrimentally. For instance, Burke (1954:133) addresses himself to the phenomenon of "exorcism by misnomer": "The notion of perspective by incongruity would suggest that one casts out devils by misnaming them. It is not the naming in itself that does the work, but the conversion downward implicit in such naming" (emphasis in the origina1). Indeed, the contemporary work of psychoanalysts bears evidence that, in some cases, effective therapy can result by the substitution of one vocabulary for another. (In some cases it can not.)

But the point that Burke is making is that, if one's task is actually to understand the meaning of human behavior, one must deal directly with the behavior and vocabulary of motives of the individual himself. Misnaming involves misconceiving. Specifically, first, men act in and interpret situations on the basis of their own orientation or logic. Therefore, to doubt the credibility of an individual's motive-rationalization for conduct is just simply to negate the fact that people do their own "minding." Burke (1954:21) argues:

To explain one's conduct by the vocabulary of motives current among one's group is about as deceptive as giving the area of a field in the accepted terms of measurement. One is simply interpreting the only vocabulary he knows. One is stating his orientation, which involves a vocabulary of ought and oughtnot, with attendant vocabulary of praiseworthy and blameworthy. 
Secondly, if a man explains his conduct within the logic of the only vocabulary he is familiar. with, it can not be argued that his rationalizations or logic are invalid or flawed. Again Burke (1954:85) argues that even the "primitive" orientations of savages is as "real". to them as conventional logic:

As a matter of fact the savages behave quite logically, acting on the basis of causal connections as established by the tribal rationalizations. We may offer ground for questioning the entire rationalistic scheme as tested by our own technique of testing--but we can not call a man illogical for acting on the basis of what he feels to be true.

Finally, misnaming or translating involves misconceiving the orientation of the individual's behavior in that the very quality most characteristic of people--their ability to interpret and choose--is ignored. For instance, whether it be by the mystic or the scientist, through trans-. lation or reinterpretation of an individual's vocabulary of motives, those motives are invariably seen as a function of ulterior or causal forces. For instance, a scientist or a mystic would interpret any given act of an individual not on the basis of his own interpretation; rather, a plethora of forces working on the individual would be introduced, ranging from "spel1s,". "devils," "libidinous drive energy," to "drives," "instincts," "norms," "roles," "social structures," ad infinitum, ad nauseum. Burke $(1954: 218)$ argues that, whatever the rationality of the translation may be, it tends,

to shape its accounts of the universal process without regard for the most characteristic patterns of individual human experience: the sense of acting upon something rather than of being acted upon by something. The spontaneous words of human motivation all imply the element of choice; but the scientific (or mystical) words imply compulsion. All causal schemes for explaining our actions begin by eliminating the very quality which most strongly characterize our own feelings with regard to our actions (emphasis in the original). 
Finally, an attempt to determine the "real" meaning of an individual's behavior through perspective by incongruity is ultimately futile. This is simply because translation can go on into infinite regression; it has no necessary end. Behavior can be interpreted through metaphor and analogy in an endless number of ways; who is to determine which translation is more "real" than another, especially in relation to the inḍividual's avowed vocabulary of motives.

To say a man's intentions were in turn shaped by prior factors is simply to open oneself to an infinite regress, which the orthodox scheme of scientific causality avoids solely by truncating its speculations. It stops at a convenient point, and interprets the convenience as cosmic reality (Burke, 1954:23).

The evidence of this fact is rampant. There exists today a "Babel" of interpretations of human behavior each competing with one another. "Such interpretative schemes, varying in their scope and thoroughness, seem limited only by the time and industry of the heuristically-minded-and our examples can be chosen at random" (Burke, 1954:117-8).

Burke argues therefore that motives should be understood as subdivisions of an individual's orientation to his environment, particularly situations. Specifically, motives are "terms of interpretation" or rationalizations that are used by the individual to justify his conduct within situations to significant others. As such, motives do not involve "causes" or "determinants" of action. They are rationalizations of actions that function as short-hand terms for situations. 


\section{CHAPTER IV}

\section{AN EXCURSIS ON CAUSE AND DETERMINISM IN \\ SYMBOLIC INTERACTIONISM: R. S. PETERS}

The sociological significance of motives, especially as developed by Burke, is that they are terms of interpretation within situations that function to rationalize an individual's behavior. In this sense, motives are not to be understood as causal or deterministic forces that control an individual's behavior. In an extended sense then, motives are theoretically relevant to only a problematic or indeterministic theory of action and meaning. Thus the direct applicability of G. H. Mead's analysis of meaning, "minded behavior," and action. (Specifically, Mead understood "minded behavior," or the dialogue between the "I", and "Me" as involving an anticipation by the individual of the responses of significant others (including one's self) within a given field of action.) But Mead forcefully stressed the variable and problematic features . involved in the establishment of meaning. Since meaning is contingent on the reciprocal and over-lapping responses of others (or the "I" toward the "Me") which are not guaranteed, the meaning of action itself is problematic and it involves indeterminate features. Thus the relevance of motives to Mead's theory of meaning and action. / Because the meaning of action is situationally problematic, and in some situations is never established, motives, as terms of interpretation, function to rationalize and justify the behavior when it is questioned by significant others.) 
In 1958 , R. S. Peters explicitly analyzed this feature of indeterminance with respect to the problem of motivation and was able then to formulate a general critique of all deterministic theories of human action.

Along. with Burke, Peters $(1958: 28)$ argues that "motives are a particular class of reasons. Many sorts of things can be reasons for actions, but motives are reasons of a particular sort." First, Peters (1958:31) argues that motives relate to action only in situations where actions are questionable and need to be justified:

A motive is not necessarily a discreditable reason for acting, but it is a reason asked for in a context where there is a suggestion that it might be discreditable. The demand is for justification, not simply explanation (emphasis in the origina1).

Secondly, motives are reasons that assign a goal for action that allude to an individual's orientation within a situation (1ike Burke's "shorthand terms for situations"):

If we ask for a man's reason for doing something, the implication is that he is acting in no untoward way. His behavior is. within the framework of some rule-following purposeful pattern, but it is not clear which rule or which purpose it falls under (Peters, 1958:33-4).

Lastly, Peters argues that motives assign the reason why a person is acting.

By this is meant that the goal which is quoted to justify a man's action must also be such that reference to it actually explains what a man has done. . . The motive must be the reason why he did whatever he did (Peters, 1958:34) (emphas is in the original).

Peters' analysis of motives thus compliments Burke's, although Peters tends to emphasize the central importance of a "question" arising within the situation that calls for a justification. At this point, however, by combining both Burke and Peters, a formal definition of motives 
is forthcoming: A motive is a justificatory reason in interactional contexts where behavior is being judged by others. It refers to a directed disposition toward a goal relative to one's orientation in a situation that explains the reason for the action.

\section{A CRITIQUE OF CAUSE AND DETERMINISM}

From this conceptual understanding of the problem of motives, Peters was able to formulate a general critique of causal or deterministic explanations of human action. The problem of action has traditionally pivoted around the question: "how does the directedness of behavior come to be?" Peters $(1958: 38)$ argues that, since motives function to justify behavior by assigning a goal toward which action is directed, many observers have attempted "a causal interpretation of the logical force of the term." Specifically,

It looks like an analysis of the concept of "motive" of a sort that implies that whenever we explain an action by reference to a motive we both assign a reason or goal and a cause. But are both elements of this ostensible analysis equally necessary (Peters, 1958:38-8) (emphasis in the origina1)?

Obviously not; the causal problem is simply an inference made by the observer that in no way is indicated by either behavior that is observed to be directed, or behavior that is justified by a motive as being directed. Basically, the attempt to assign causal or deterministic force to either the directedness of behavior that is observed or explained by a motive is on highly questionable grounds. This is so, Peters argues, because the inferred causal or deterministic explanation amounts simply to redescription of a tautological account of the behavior. (For instance, the directedness of one's behavior can be observed or avowed by an individual as an attempt to control the conduct of other people around 
him. A causal or deterministic interpretation can be inferred from this observed behavior or motive-avowal as involving, say, a need to dominate others. But Peters $(1958: 20)$ argues that, all too often this type of functional or end-state explanation is redescriptive rather than explanatory . . ." For instance, with respect to the example above, "what is the condition [or need] restored apart from that of the presence of others being dominated (Peters, 1958:20)? Peters (1958:20) argues that

in the absence of specific states required to define what constitutes the [need], it becomes entirely metaphysical . . . Indeed in such cases need-reduction looks like a redescription. of goal-seeking in terms which have the normative function of stressing the importance of conventionally prescribed pursuits. It is a justification masquerading as a high-level explanation.

The issue here is one of "tautology." The directedness of action can be either observed, or if questionable, explained by the individual through motive avowal. But any causal force that is attached toward the observed behavior or the avowed motive is merely an inference created by the observer. Furthermore, this causal inference of the observer constitutes nothing more than a redescription of the actual behavior, except in deterministic terms. This is the basis of tautology: that which is used as evidence of something is then explained by that something. For instance, an observed behavior (dominating others) is used as evidence of some term (a need, etc.) that is then explained by that term. As Peters argues, this is redescription or tautology, and its explanatory value is nil (see Stone, 1970).

Causal or deterministic explanation of the directedness of behavior is marked by another discrediting characteristic. Namely, not only is deterministic argument fundamentally tautological, but the inferred "cause" can vary among an infinite number of imagined sources. As Burke argues, 
causal explanation involves the possibility of infinite regress. Tautology, being fundamentally metaphysical, can enumerate an infinite number of "causes" that affect the behavior, from "devils," "needs," to social "norms," and "roles." The range of possibilities is limited only by the imagination of the theorist.

Peters underscores this point by a similar argument. Causal or deterministic explanation assumes that "other conditions being presumed unchanged, a change in one variable is a suffictent condition fop a change in another" (Peters, 1958:12) (emphasis in the origintl): But the trouble about postulating this kind of an explanation is that there are an infinite or at least innumerable numbep pf "conditfons" that would have to be specified and controlled in demonstrating a determintstic explanation.

Now the trouble about giving this sprt of explanation of human actions is that we can never specjey an actipn exhaustively in terms of movements of the body of within the body. It is therefore impossible to state suffident opnditions fin terms of antecedent movements which may vary concomitantly with supsequent movements (Peters, 1958:17)?

Peters therefore argues that causal and deterministic anguments, far from lending insight, function father fo mystify human action or explain it through redundancy, First, causel pr deterministfo explanation is fundamentally tuatological: that which is used as ovidence of something is thep explained by that something: Secandiy, causal axplaniation is mystical in that the alleged causes of behavior, whether that ba demons, instincts, or needs, etc., âre primarily derivates of the figment of a theorist's inference. And lastly, causal or deterministic argument is fundamentally futile since all of the conditions can never be specified or controlled that would demonstrably permit observation of the effect of one variable on another. 
The over-riding point, however, and one that underlies the entire critique of causal explanation, is that in daily life individuals manage to comprehend and control their respective behavior, not via general theories or causal explanations, but by ad hoc or situationally specified accounts. On the basis of motive-avowal behavior typically flows smoothly and finds justification within the contingencies of situations themselves. As such, ad hoc explanation in daily life is efficacious and germane.

When we [laymen] offer explanations of human behavior, we are seeing that behavior as justified by the circumstances in which it occurs. In appealing to reasons for acting, motives, purposes, intentions, desires, and the cognates, which occur in both ordinary and technical discussions of human doings, we exhibit an action in the light of circumstances that are taken to entitle or warrant a person to act as he does (Louch, 1969:' 4).

\section{DETERMINISM IN SYMBOLIC INTERACTIONISM}

In the realm of science, however, ad hoc explanations of human behavior will not suffice. Indeed, the task of all behavioral science, including sociology, is an attempt to transcend the ad hoc and formulate generalization of human behavior within the parameters of a general philosophy of science. Specifically, sociology, in formulating theories of action, has been concerned with theories of behavior that not only theoretically generalize across situations, but also attempt to predict and explain behavior. It is because of this that law-like, or deterministic theories of behavior have arisen. As Louch (1969:40) argues, with respect to any philosophy of science,

The test of explanation is its scope; the number of instances which can be seen to follow from it is a clear and objective way of assigning plus marks. To admit ad hoc explanations, on the other hand, is to allow instances of proper explanations which do not meet any particular standard. 
In addition to the problem of scope or generality, however, is the problem of prediction. This involves what can be roughiy coined as "variable analysis"; changes in specified variables are used to predict changes in other variable, thus involving a clear deterministic bias. Thus, as Blumer (1967:89) argues,

The conventional procedure is to identify something which is presumed to operate on group life and treat it as an independent variable, and then to select some form of group activity as the dependent variable. The independent variable is put at the beginning part of the process of interpretation and the dependent variable at the terminal part of the process.

Needless to say, much of symbolic interactionism has not remained aloof from this practice; due to a reverence and preoccupation toward the canons of a respectable science, symbolic interactionists since Mead have developed a number of deterministic or law-like theories that generalize about the nature of human doings. This has been justified in a number of ways. Kuhn (1967:48-9) flatly argues that, "This internalization of language and the concomitant internalization of the role of the other has, in the Meadian description, nothing in it inconsistent with strict regularity or determinism." Kuhn also footnotes Swanson (1961:327) as saying, 'Mead's account [of conduct] . . is not opposed, in principle; to a deterministic view of behavior." However, Kuhn (1967:49) does recognize that Mead indicated that "the "I" is impulsive and essentially unpredictable--and furthermore that the "I" is the initiating, acting aspect of the self." But Kuhn (1967:49) excuses away these assertions so fundamental to Mead by arguing that Mead's arguments were "elusive" due to the fact that he orally presented his philosophy as opposed to writing it, and that therefore, "It is never completely clear whether he meant only that the $I$ is subjectively unpredictable or that it is indeterminate in a scientific sense. ${ }^{5}$ As was clearly argued above, Mead explained that 
the response of the "I" was both subjectively uncertain (one surprises one's self), and that this can be empirically and scientifically observed: men bungle their actions frequently.

None the less, variable "or deterministic analys is has proceeded" in symbolic inţeractionism, and indeed, it now dominatop in most varieties of symbolic interactionism. For instance, Kuhp notes seven general sub-tyges of symbolic interactionism rolo theory, referenco group theory, social (and personal) perception theory, self theory, socialization and career theory, language and cultuf̣al orientatipn, and dramaturgy. Further, he notes that only dramaturgy and socialfagtion and career theory couches an indeterminate or émergent point of view (see Kuhn, 1967:56-7). ${ }^{6}$ He does note that language and cultural orieptation is also indeteminate, but that actually this orientation is not symbolic interactionism theory put philosophic position developed by Iingual philosophers (Sapir, 1221; Whorf, 1956; and Cassier, 1953-5) that underIie sympolic interactionism, Therefore, within symbolic interactionism proper, there are basically four deterministic theories opposing two indeterministic positions.

Kuhn goes further and graphicaliy sketches out the "variable analysis" af deterministic symbolic interactism. Role theory, self theory, reference group theory, and social (and personal) perception theory advance one or more of the following arguments:

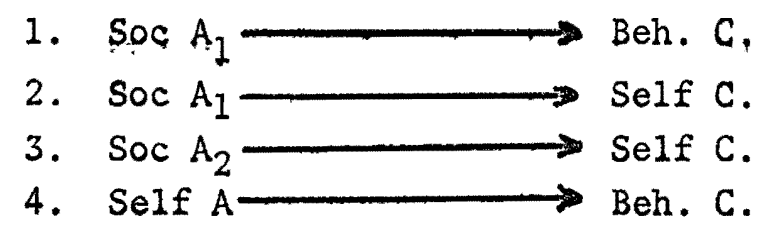
where, 
Soc refers to a social variable

Self refers to a self variable

$A_{1}$ refers to an immediate antecedent variable

$\mathrm{A}_{2}$ refers to an antecedent but distal variable

$C$ refers to consequent variable

Beh. refers to behavior

Solid arrow indicates a determinate causal process

(Kuhn, 1967:50)

While it is not our intent (nor even a possibility within the limited objectives of this essay) thoroughly to treat each theory with regard to its own idiosyncracies or persuasion, Kuhn's diagram will at least afford the basis of a general understanding and critique of deterministic symbolic interactionism.

Determinism enters symbolic interactionism through a very simple modification of Mead's basic premises concerning the relationship between the "I" and the "Me." Specifically, instead of "taking the role of the other," the individual is seen to be "taken by the role of the other." 7 This is accomplished by hypostatizing the "Me," and further engendering it with powers to manipulate and govern the response of the "I." In this sense the "Me" is made into an object or a collection of objects that in scientific verbiage can be referred to as an objective variable. As in role theory, the "Me" becomes a collection of objects such as expectations, norms, and rules that direct the response of the "I." Or, in reference group theory, the "Me" becomes an object such as an organized collection of attitudes, values, mores, and folkways relative to a particular group that, as Shibutani (1967) says, acts as a "frame of reference" in directing the response of the "I." In early socialization theory the "self" was typically regarded as a function of "roles," or as Backman and Secord (1968:289) say, "This linkage has for the most part taken the form of role as the independent variable and self as the dependent variable." 
Now, however, "self theorists" have engendered "self" as a more permanent object that can be argued to determine its own role:

The reverse of this fashioning of self by role may take two forms: role selection and role portrayal. In role selection, a person chooses roles that allow him to behave in a manner compatible with self; in role portrayal, when the role provides wide latitude for enactment, he favors the portrayal that is most consistent with self (Backman and Secord, 1968: 289) (emphasis in the original).

As this latter example indicates, the variables or objects in deterministic logic are interchangeable and relatively arbitrary; selves can be a function of roles, or reference groups can be a function of selves.

The remarkable flexibility of such schemes is due to the fact that their logic is tautological. Again we can use some other studies by Backman and Secord $(1961 ; 1965)$ to demonstrate this. Their.studies have been "guided by a social-psychological approach to personality, which assumes that stability and change in an individual's behavior over time is a function of stability or change in his relations with other persons" (Backman and Secord, 1968:289). But is not a relationship toward other people the way one behaves toward them? Through tautology, however, the "relationship" becomes a thing in itself, just as "roles," "reference groups," and "selves," become a thing in themselves. The logic proceeds as follows: a given behavior is used as evidence of another phenomenon or object which can be arbitrarily stated--norms, roles, selves, reference groups, sub-groups, whatever. This object is then made into an independent variable and the original behavior is then argued to be its derivative. Douglas (1967:241) argues this same point except in terms of sociological theories in general: 
[Theorists] assume that the observable phenomena are representative of their theoretical categories. Such analyses of social phenomena really tell us nothing of a scientific nature: they consist primarily of merely imposing upon the immediately observable phenomena . . an abstract set of assumptions about the nature of society, assumptions which can be applied anywhere to any social phenomena.

The point is, though, that through tautology the independent and dependent variable amount to one and the same thing; except conceptually recast, divided, and hypostatized. In this sense deterministic theories in symbolic interactionism are "sustained not by evidence, but by the interdependence in meaning of the terms out of which... laws are formed" (Louch, 1969:14). Moreover, as Louch (1969:12-13) argues,

We understand the verbiage of the superstructure a little better when we see what count as instances of his terms and rubrics. In this sense the theory has no explanatory power; and as a description is unnecessarily complex.

The only significance of sociological tautologies is that of a "surprise [that] arises only in that what we know already about human activities can be re-phrased in this terminology and classificatory system" (Louch, $1969: 12){ }^{8}$

Deterministic theories in symbolic interactionism can therefore be seen as involving a strong mystical cast. Through tautology, norms, roles, selves, and other objects are argued to exist and in fact determine behavior. Yet, except for the actual behavior how can one observe norms, roles, selves, or frames of reference? One can not, for they are a product of theoretical abstraction and tautology. They are as real or unreal as the abstractions of mystics: demons, devils, and curses are equaliy unobservable.

This brings us back to Burke's notion of "perspective by incongruity." An individual's behavior can be interpreted or translated in an infinite 
variety of causal arguments, primarily through the use of redescription and tautology. To suggest that a man's actions were determined by prior factors simply opens one's self up to "infinite regress" and speculation.

Tautology is not the only discrediting feature of deterministic explanations in symbolic interactionism. In the process of redescribing behavior, tautology also conceptually ignores and obliterates features of behavior that do not fall within the confines of its focus. Specifically, in delineating the interaction between the dependent and independent variables, the intervening process drops out. What is left out is precisely what Mead attempted theoretically to establish; namely, that meaning is processually contingent on the over-lapping and reciprocity of responses of individuals within behavioral situations. Let us look at the latter problem first, that of situations.

In deterministic symbolic interactionism, situations are relatively unproblematic and inconsequential. The meaning of the behavioral interaction is seen to be contingent on antecedent, independent variables. What takes place is seen to be casually dependent on that variable. Yet Mead maintained a constant posture toward recognizing the tentativeness of meaning within situations. Responses are not necessarily forthcoming, or they can be inappropriate. Moreover, the situational environment can be inappropriate for a given interaction, or invaded by others causing interruption or disclosure of secretly guarded information (see Blumer, 1971). The point is that meaning is established in interaction, and interaction occurs in situations. A host of complexities is therefore situationally introduced. But as Strauss (1969:61) notes:

A scientific vocabulary fashioned along the lines of "cues" or "stimulus response" or "the unconscious" or "needs and drives" or merely "role-playing" and "status" and "self-conceptions" will tend to by-pass rather than handle its intricacies. 
Deterministic symbolic interactionism also misses the complexities of action and meaning itself. As Kuhn's diagram indicates $(p, 35)$, behavior becomes unproblematic, a variable dependent on variously conceived deterministic forces. But Mead was very much opposed to this: responses are always uncertain--the response called for:by the "me" involves a moral, not mechanical, necessity. Action in this sense is problematic. As Strauss (1969:57) illustrates, "I can explode quickly, without reflection, at one of my own responses. I can dimly experience feelings about my performance without being clear what exactly I am experiencing." In short, therefore, behavioral meaning must be seen as fundamentally problematic, and a full understanding of it requires a comprehension of the complexities and relevance of both situations and actions. One can even go a step further and suggest that, in order to comprehend fully the complexities of meaning, explanation of behavior might better incorporate an "indeterminate" stance toward behavior. The point is, when can all the conditions and significant variables be stated that can explain the meaning of a given interaction? As Strauss (1969: 33) notes, "The reappraisal of past acts and the appearance of surprise in present acts gives men indeterminate futures."

\section{THE CONCEPT OF EMERGENCE}

Without ardently rejecting the entire position of deterministic analysis, some notable symbolic interactionists have recognized its inappropriateness and inadequacy in conceptualizing the complexity of meaning in social interaction. Blumer (1969:2-3) in particular has continuously emphasized the significance of both the "situation" and "actions" within the situation as key elements in the building up of social meaning: 
Common to both of these fields [psychology and sociology] is the tendency to treat human behavior as the produet of various factors that play upon human beings; concern is with the behav- 4 ior and with the factors regarded as producing them. . .

[Thus] in both such typical psychological and sociological explanations the meanings of such things for the human beings who are acting are either bypassed or swallowed up in the factors used to account for their behavior.

Bolton (1963:7) has coined the deterministic stance in sociology as a "Behavioral Science ideology" and has noted that it conveys an image of man as involving "a mechanical response to or expression of some other activating force-that is, a reaction to stimuli, to organic tensions, to internalized norms, to social situations, to dysfunctional changes, etc." He sensitively notes that meaning in social acts "are constructional in character; they are built up rather than being simply learned responses" (Bolton, 1963:104) (emphasis in the original). (Bolton (1963:8) argues that an appropriate image of man in sociology and symbolic interactionism can be "neither than of a 'behaver' nor 'actor', but that of 'interactor'.) By viewing the basic individual unit as 'interactor' a connection is immediately made with two crucial sociological factors, situation and transaction."

As opposed to strict deterministic models, Bolton therefore argues that the concept of "emergence" is more appropriate for conceptualizing the building-up of meaning in terms of situations and actions. (Emergence "refers to the process in which the combination of elements having a given set of properties produces a new form having properties not characteristic of any of the elements making it up" (Bolton, 1971:16). 'Obvious$1 y$, the concept of emergence is an attempt to get at the "intervening processes"! of situation and action./ The deterministic notion that the meaning of behavior is located in antecedent or "before the fact" vari- 
ables is clearly rejected. As Bolton (1971:2) argues,

the outcome of the episode is not predictable just from a knowledge--however complete--of the personality, cultural, social structural, or other factors existing at the outset of the episode, but that the outcome of the episode is also significantly shaped by the interpersonal and intrapersonal processes that occur during the episode.

However, this is not to suggest that the proponents of emergence have given up on deterministic analysis; indeed, the very opposite is the case. Proponents of emergence are still eager to affirm the basic assumptions of positive science in assuming that nature, including human behavior, functions according to naturalistic logic; "given the correct technique on the part of the practitioner, the invariable causality of. the world can be made into one's bidding" (Burke, 1954:59). As Bolton (1971:3) explains,

But, though these latter processes are not to be understood as mechanical manifestations of pre-existing structural and socialization conditions, there is no implication that they are not explicable in naturalistic or deterministic terms--albeit . . . this naturalistic explanation must partially lie in processes of emergence and creativity, both of which may be given an acceptable scientific grounding even though both may defy prediction in advance.

The special "technique" recommended for the deterministic analysis of emergent acts is that of "replication." First, it is argued that, with respect to any emergent act, the relevant conditions such as social structure, roles, situation, roles, etc. (the traditional sociological variables), that are involved prior to the act must be noted. Then, after an emergent episode one must further delineate all "the conditions under which an emergence or creative act has occurred." Then it is argued that by replication a scientific prediction can be formulated of a similar creative event occurring under similar conditions, such as a scientific break-through, or parallel inventions. 
Our retort, however, is that this is exactly the point; after the fact or retrospective explanations lie at the basis of man's comprehension of the sense and logic of his behavior. Indeed, this is Mead's point.* However, this is not to affirm that a given event or one's behavior follows naturalistic logic, but rather that the logic is a rationalization retroactively applied to the behavior. The technique of "replication" therefore merely beefs up the role of rationalization as explanation and dresses it in scientific verbiage. But like rationalization, itself, it has no explanatory power, but merely justificatory ability. The notion of "replication" is a cleverly articulated conception of justification, not scientific explanation.

Obviously this again introduces the relevance of motives in human behavior. Motives are used to justify and rationalize questionable behavior. But they do not imply, nor can one infer, causal or deterministic sense in behavior on the basis of its rationalization. It has already been indicated why this is so. First, referring back to the technique of "replication" involved in the notion of emergence, when can. all the conditions be specified? As Burke and Louch argued, they can not. Specification of necessary conditions can go on indefinitely and it involves infinite regression. As such, most theorists simply stop at a convenient and arbitrary point, and "interpret this convenience as a cosmic reality" (Burke, 1954:231).

As noted earlier, therefore, the relevance of motive falls within an indeterminate theory of human action. It is only because, as Mead

*As quoted above: "It is only after we have said the word we are saying that we recognize ourselves as the person that said it . . .; it is only after we have done the thing that we are going to do that we are aware of what we are doing" (Mead, 1934:203). 
originally argued, that actions and responses are continuously uncertain and tentative, that motive-justifications become germane to behavior. What one frequently objectifies as the sense or logic of action is an imputation after the fact in the form of justification or rationalization. In this same reasoning, the meaning of actions is also tentative; in terms of the over-lapping and reciprocity of responses many actions are not meaningful. As Mead (1934:142) illustrated, "We realize in everyday conduct and experience that an individual does not mean a great deal of what he is doing and saying. We frequently say that such an individual is not himself." And thus bespeaks the significance of rationalization.

\section{BRIEF SUMMARY}

Louch argues that due to the sociologists' pre-occupation with methodology and proper scientific form, the study of human behavior has been led into redundancy and irrelevance. "It has led sociologists and psychologists to design their studies in accordance with some conception of proper form and almost wholly, without reference to the subject matter. In consequence the putative laws are often thinly disguised tautologies" (Louch, 1969:9). Specifically, Louch (1969:1) argues that

Behavioral scientists... and philosophers have put obstacles in the way of ad hoc explanations by demanding that any explana-. tion lean on generalities for its support. When these demands are taken seriously . . theories are developed which meet the formal requisite of generality, but which pay the price for it rather heavily. For these theories are often redundant and platitudinous or totally irrelevant to the behavior they are designed to explain.

It is in this sense that motives have typically been construed as involving underlying causes or forces that constitute the "actual" or "intended" meaning of an individual's behavior. However, this is 
obviously not the case. Motives are terms of interpretation that justify an individual's behavior by referring to one's orientation within a given situation. As such, they are situationally relevant, but hardly otherwise. But social scientists feel that "motive accounts seem defective because of their rough edges, their tentativeness" (Louch, 1969:101). But this is because actions are themselves tentative. As Louch (1969:101) concludes, "There simply are cases in which the ascription of motives is tentative and vague, not because our tools are inadequate, but because human action is often fundamentally ambiguous, often aimless, frequently equivocal." 


\section{CHAPTER V}

\section{WRIGHT MILLS' SOCIOLOGICAL IMAGINATION}

C. Wright Mills was not a champion of ad hoc explanations of social conduct either. Priding himself in taking a "classical" stance toward social phenomenon, or delineating that fine intersection between history, social structure, and individual biography, Mills consistently attempted theoretically to see the "Big Picture" (cf. Mills, 1959). Thus it should be of no surprise to find that, while his 1940 paper was the first explication of a truly sociological explanation of motives, Mills also argued that motives, as lingual vocabularies, were aspects of larger social factors such as "social groups," "societal frames," and "historical epochs." He also argued that motives were not merely justifications or. descriptions of questioned behavior, but also functioned to "stabilize and guide behavior and expectation of the reactions of others" (Mills, 1962a:449): Thus he introduced a clear deterministic bias in terms of what he called the "social function" of motives.

\section{CONSEQUENTIAL SITUATIONS AND SURROGATES FOR ACTION}

Mills (1962a:440-1) correctly argues that motives are justifications in situations where conduct is questioned: "For men live in immediate acts of experience and their attentions are directed outside themselves until acts are in some way frustrated. It is then that awareness of self and of motive occur." Moreover, "the 'question' is a lingual index of such conditions" (Mills, 1962a:441). As such, motives do not 
refer to anything "in" persons, but, "They stand for anticipated situational consequences of questioned conduct" (Mills, 1962a:441).

As a word, a motive tends to be one which is to the actor and to the other members of a situation an unquestioned answer to questions concerning social and lingual conduct. A stable motive is an ultimate in justificatory conversation (Mills, 1962a:443)

(emphasis in the original).

It should be remembered that by 1940, Mills' argument above represented the first explicit sociological analysis of motives, and that Mills was relying heavily on the works of Mead and Burke. But Mills also did more than merely sociologically integrate Burke with Mead. He argued that the significance of motives as merely justifications of questioned conduct was not to deny their efficacy and function in social behavior (see Gerth and Mills, 1953:116). Specifically, Mills (1962a: 441) argued that "individuals act in terms of anticipation of named consequences" (emphasis in the original). And because motives are names of consequential situations, they are also "surrogates for actions leading to them" (Mills, 1962a:441). Mills argues that what this involves is that, in situations where a question is raised, motives act as an "integrative cue" to others with regard to their cooperation or involvement in the future completion of the situated actions.

The societally sustained motive-surrogates of situations are both constraints and inducements... such words, often function as. directives and incentives by virtue of their being the judgements of others as anticipated by the actor (Mills, 1962a:445) (emphasis in the original).

In this sense Mills is arguing that the social function of motives is that they integrate action toward others by justifying the present program of action and also call out or induce reciprocating responses from others. In this way, Mills (1962a:449) argues that "Vocabulary of motives ordered to different situations stabilize and guide behavior and 
expectation of the reactions of others."

In developing a sociological explication of motives, Mills therefore takes a considerable step further than simply arguing that motives should be conceived of, not as causes, but justifications of behavior. First, Mills argues that the role of motives is not simply "after the fact" of a questioned act in terms of justifying it. But the avowed justification or motive is centrally influential as a "before the fact" phenomenon in terms of calling for a particular response from others, and stabilizing and guiding behaviors in the next act. Or as Mills (1962a:445) argues, motives function as "constraints and inducements... directives and incentives" for others and one's self in constructing the next act (emphasis in the original).

But there is a conceptual problem here, if not a contradiction. Motives as "justifications" are "after the fact" with only problematic and unspecified significance toward later interaction. However, motives as "surrogates of action" that call out and guide responses from others in building up following acts take on a deterministic or causal bias, almost akin to the traditional notions of motives. Mills was aware of this determinism, however. He hypothesized that "typal vocabularies of motives for different situations are significant determinants of conduct (Mills, 1962a:445). He also clearly stated that "Vocabularies of motives order to different situations stabilize and guide behavior and expectations of the reactions of others" (Mills, 1962a:449). Moreover, it is absolutely essential to Mills' (1962a:444) argument that motives act as an "integrative factor in future phases of the original social action or in other acts". (emphasis in the original). 
But on what logical basis can one argue that motives, even within this lingual-sociological sense, can be said to influence or determine conduct? Only one, and that is ex post facto logic, of rationalization "after the fact." This is for obvious reasons. Can the nature of a response, or even a response itself, be predicted or guaranteed "before the fact" on the basis of a motive avowed? No; human responses are always uncertain, tentative, and even surprising. All one can do is hypothesize that motives guide and stabilize conduct; their actual effect can only be ascertained by observing a given interaction wherein motives are avowed, and then "after the fact" argue that later events were influenced by motives themselves. Again, however, this logic is rationalization. Furthermore, if one wants to hypothesize "causes" or determinants, one has an infinite number to choose from because this effort involves infinite regression.

The problem actually gets down to the question--what is the social significance of motives? Mills begs this question by an a priori or "before the fact" assumption that motives function to integrate others into the social act by calling out responses in others, and thereby guiding and stabilizing conduct. Mills here is attempting to use motives in a vein similar to that used by others concerning "rules" and "norms." It is explained that interaction flows smoothly because "rules" and "norms" or "roles" (or "motives") guide and stabilize conduct. But the meaning of motives can only be ascertained by noting the way others respond to them, and this is problematic across situations. Motives, as justifications, can be accepted, rejected, or ignored. Their meaning in action is determined by the way they are acted upon; thus their meaning is an on-going problem. Avowed motives do not guarantee particular 
responses: Like other theorists, Mills is too anxious to explain behavfor: For instance, he even argues that motives are "unquestioned answers to questions concerning sopial and lingual conduct" (Mil1s, 1962a:443). And in doing so he begs the problem of behavioral meaning, Because the meaning of any social "factor" is dexived in terms of the fesponse it receives, stating the problem in reverse amounts to begging the guesfiop through tautology. Put simply, the response is not due to the minging of the motive; rather, the meaning of the motive is given by the $\rightarrow+r^{2}$

Mills argued that motives have a deterministic effect on other!s actions. Othef theorists have mused over this problem, notably Netpon Foote in 1951, and he argued that the relationship between wards and actions as outfined by Mills was somewhat "mysterious," Fogte therofope attempted to explicate the significance of motives as "pefare the fact!! phenomęnon. In doing so he remphasizes Mil1s' determinism and draws the taytology to its natural conclusion. 


\title{
CHAPTER VI
}

\author{
NELSON FOOTE ON IDENTIFICATION
}

As Becker (1964a:110) argued, motivation was no problem for Mills:

Motivation was thus no problem for Mills, and he used the familiar concept of role as a superordinate performance category by means of which the individual is led on. Roles tell the individual how to act for maximum self-satisfaction and facilitation of conduct.

Moreover, as late as $1953 \mathrm{Mills}$ was still subordinating the problem of motivation to an aspect of role theory. For instance, as Gerth and Mills (1953:11) argued:

Man as a person is an historical creation, and can most readily be understood in terms of roles which he enacts and incorporates. - . His memory, his sense of time and space, his perception, his motives, his conception of self... his psychological functions are shaped and steered by the specific configuration of roles which he incorporates from his society.

Foote also came to the problem of motivation via role theory. The first sentence of his paper is that "Role theory has suffered since inception from lack of a satisfactory account of motivation" (Foote, 1967:343). The deficiency of role theory, he argues, is that, while it can explain "standard situations" adequately, it can not explain situations that involve role conflict, apathy, or abandonment. "A striking revelation of the need for some theory of motivation.. . is disclosed by apathy in the performance of conventional roles, when these are on the verge of abandonment, or are accepted only under duress" (Foote, 1967:343). Foote (1967:353) therefore sets forth that "role theory needs to be supplemented with an account of motivation consistent with its main premises." He 
cites Mills as dealing with this problem, especially with reference to. motives as justifications. But he criticizes Mills' paper because it

leaves the reader with the uncomfortable feeling of an unanalyzed hiatus between words and acts, of mystery as to just how language does in fact motivate. It is this hiatus which the concept of identification seems adequate to fill (Foote, 1967: 344).

By "identification" Foote (1967:347) means "appropriation of and commitment to a particular identity or series of identities. As a process, it proceeds by naming; its products are ever-evolving self-conceptions--with the emphasis on the con--, that is, upon ratification by significant others." Foote argues that, in situations of role conflict or abandonment, one can not know what to do unless one knows who he is. "Moreover, he must know who he is with considerable conviction and clarity, if his behavior is to exhibit definiteness and force, which is to say, degree of motivation" (Foote, 1967:346).

Foote (1967:345) then defines "motivation" as referring

to the degree to which a human being, as a participant. in the ongoing social process in which he necessarily finds himself, defines a problematic situation as calling for performance of a particular act, with more or less anticipated consummations and consequences, and thereby his organism releases the energy appropriate to performing it (emphasis in the original).

However, identification underlies the problem of motivation because, Foote argues, within any given situation, one can not know what is expected of him (or what the situation calls for) unless one knows one's identity. Says Foote $(1967: 350)$ :

Only full commitment to one's identity permits a full picture of motivation. Faith in one's conception of self is the key which unlocks the physiological resources of the human organism, releases the energy (or the capacity, as Dewey would say) to perform the indicated act.

Thus identification is argued to be the basis of motivation. 
One could argue here that Foote is merely arguing in circles: knowing what one is supposed to do is knowing what one is, and vice versa. To use one of Foote's examples, if one is expected to stand on "first base" and catch the ball before the "runner" touches the base, one knows not only what to do, but also who he is. He is the man who stands on first base and catches the ball before the runner touches the base. Furthermore, if one knows he is expected to do this for nine "innings," then he knows that he is committed to this identity for nine "innings." The relationship between identification and motivation as Foote sets it up therefore seems to be quite pointless. Foote also says that both the processes of identification and motivation "release" the energy for the given act. But which process comes first and what their actual differences are remains quite obscure.

However, Foote is trying to grapple with the problem proposed by Miller: how does one know what to do when situations are confusing and actions are questioned? Foote argues that this, in fact, is the problem of motivation. Now Mills argues that motives justify behavior by naming anticipated consequences of one's action with reference to other's actions. These justifications can then be said to represent "surrogates of action" that cue in or integrate others, and guide and stabilize future actions. Foote $(1967: 344)$ claims that this is still somewhat of a mystery because Mills does not tell us "just how language does in fact motivate." Thus the hiatus between words and acts. Foote therefore argues that, by fiat, motivation is the problem of the individual defining a situation as calling for a particular act (on the basis of finding out who he is), "and thereby his organism releases the energy appropriate to performing it." Foote (1967:345) axgues along with Mills 
that motives, as surrogates of action and names for consequential situations, function along with other cues not only to call out responses by organizing "acts in particular situations but [also] make them recognizably recurrent in the life-history of any person or group."

\section{A SUPPLEMENT TO ROLE THEORY}

The way in which Foote sets up the problem of motivation it is, indeed, a supplement to role theory. ${ }^{9}$ By fiat, motivation is actually a problem of "role-identification" or "role appropriation." Defining a problematic situation as calling for a particular response is the process of identifying one's role. Identification of who you are and what one is supposed to do (which is the same thing!) is therefore the basis of motivation. The significance of all this is that it makes, as in Mills' case, the problem of motivation a "before the fact" phenomenon. People are seen to act on the basis of identifying what the situation calls for, as indicated by various cues, such as motives, identities, etc. Or, action is said to "be released" or to proceed after one has defined the meaning of a situation as calling for a particular response. As in Mills' case, action is therefore seen to be a result of the meaning of definition of the situation calling for a particular performance on the basis of various motive-cues. Only then is energy released. This is actually a typical account of action in symbolic interactionism. As Brissett (1971:6) explains:

The conventional notion in most symbolic interactionism has been that persons come to situations, define these situations, and then (and only then) act in these situations. The "definition of the situation" in this point is essentially mentalistic; it is an interpretation one makes of or upon his environment. Whether this interpretation be labeled "dynamic assessment," "definition of the situation," or "creation of the object world," the defining ele- 
ment functions the same. Men act after they have identified and conceptualized their environment (emphasis added).

In Foote's case, as with most other forms of conventional symbolic interactionism, action is seen to be the result of either the meaning that one confers upon the situation, or the meaning of the situation as it calls for a particular response as indicated by various cues such as motives, roles, etc. With respect to Foote one wonders whether the situation calls for a response, or one defines the situation as calling for a response. But in either case, action is said to "be released" and contingent on a "before the fact" phenomenon; namely, the meaning of the situation. As in role theory, action is contingent on the meaning of the role. Or in other forms of conventional symbolic interactionism, action is contingent on the meaning of reference groups, or the self, or the social structure--or however meaning is hypostatized.

In fact one can formulate the "Grand Theory of Motivation" 10 in traditional symbolic interactionism: response is based on the meaning of the situation (also called the "definition". of the situation) as indicated by vocabularies of motives, roles, identities, selves, reference groups, social structures, ad infinitum. ${ }^{11}$ But unfortunately, at the basis of this "Grand Theory of Motivation" is its own Achilles Heel-"The Grand Sociological Tautology." The creation of the sociological tautology goes as follows. A given situation is observed to involve a given meaning. This meaning is then hypostatically interpreted as a kind of existent object, say, a role, definition, or value, etc. (a number of arbitrary metaphors are used). Then this "object" is used to explain the resultant actions of the individuals within the situation. But because the argument is circular or merely redescriptive, it has no explanatory 
value. Specifically, action is not the result of the meaning or definition of the situation, but the situation derives its meaning from the response to it. And this is why philosophic logicians like Louch (1969: 9) bluntly say, and with good reason: "Triviality, redundancy, and tautology are the epithets which I think can be properly applied to the behavioral scientist."

\section{THE HIATUS}

The meaning of a vocabulary of motive, situation, role, self, reference group, and all other sociological variables, is created and established by the response to it. Even the significant symbol, as Mead (1934:84) consistently argued, is always dependent on "the context in terms of which, or as the field within which, significant gestures or symbols do in fact have significance." And meaning is determined by response. Thus by its very nature, meaning is an "after the fact" problem within an indeterminate field of action responses. Meaning involves, as Mead said, a moral necessity, but no mechanical necessity.

Thus the hiatus between words and actions inevitably remains because the meaning of response is an "after the fact" problem that is always tentative. Response creates the meaning of language; just as the "I" creates the meaning of "Me." But response is uncertain and problematic. Unfortunately because symbolic interactionists have been so anxious to explain away the response, we have little idea of how problematic it is. But even within the daily events of everyone's life there is constant discrepancy between what one expects from others and one's. self, and what actually happens. And the significance of motives, as justifications, is that they rationalize this discrepancy of action, but they do not deter- 
ministically explain it. The significance of motives, as Lyman and Scott (1970:112) argue is "its ability to throw bridges between the promised and the performed; its ability to repair the broken and restore the estranged." 


\section{CHAPTER VII}

\section{ERNEST BECKER'S CRITIQUE OF MILLS}

No theorist has conceptually focused on the hiatus between words and actions as vividly as Ernest Becker. In his analysis of Mills' social psychology, it is failure on the part of Mills to deal with this hiatus that amounts to Becker's most emphatic criticism. As Becker (1964a;118) explains:

And in order to understand this phenomenon we have to pick up one historical current that was not elaborated in Mills' social psychology. This permits us to evaluate Mills' social psychology from still another point of view: that of phenomenology:

The main emphasis of phenomenology in social psychology is that meaning must be seen as an on-going accomplishment predicated on the behavior or action of the organism toward its object-world. The emphasis is on the ability of the organism to act toward objects and therein create a relationship with the object. Now this must be emphasized since action toward objects is not an automatic given built in to the human organism. Rather, the organism, through trial and error experimentation, develops the ability to act. In the human's case, the problem is even more complex since it is only humans that develop a reactive capacity toward symbolic objects (see Becker, 1962a). But phenomenologists ardently stress the independence between objects (including symbols) and actions.

Becker notes that other theorists have depicted this hiatus as a mind-body dualism, or more appropriately stated, a dualism between sym- 
bolic thoughts versus action. There is a separation that is only over. come, and then only partially, by the experience of the individual in acting. Says Becker (1964a:120):

Now, this self-body dualism, as we would expect, is not uniform in everyone. That is to say, some of us pay more attention to the external world, act in it more, test ourselves with the outside of our bodies. Others among us act less in the external world, shrink up more within themselves, feed ourselves on thought or fantasy, take refuge from the demands of the outside, expand our inner life, and nourish ourselves on it.

The important point, however, is that "words mean little to the development of our total personality unless we connect them up with some kind of lived experience" (Becker, 1964a:121).

Becker concludes that if Mills would have incorporated this phenomenological point of view in his social psychology, he would have realized that situated actions, far from being guided and controlled by vocabularies of motive, are frequently made progressively more tentative and unpredictable, especially in complex urban environments. The problem for the individual is precisely in being able to control and initiate a response within problematic situations (see Becker, 1964a:122). In this sense, Becker (1964b:23-4) is arguing that "meaning is won by behavior, not merely by registering experience." Thus for meaning to be established on any level or situation, "the organism must be able to call up a response to it" (Becker, 1964b:19). But human reactivity is not automatic; rather it is problematic. Mills and Foote failed to emphasize this in their social psychology because response was largely begged and explained away. Moreover, theorists in general have been so used to explaining away the complexities of bodily responses as being remotely controlled or directed by roles, norms, motives, symbols, and other social "forces" that the problematics of action have been largely 
ignored.* But as Becker (1964b:15) argues, "Behavior, energy-conversion are primary. Symbols [and other social factors] are gadflies that edge the organism on, but it is the organism that edges." Moreover, it is the organism that, if capable, uses the social "object." For instance, as Becker (1964b:15) argues:

symbols enter in only to facilitate and enrich the process. . . [but] it is the organism that uses the symbol, that must tend away from or toward the object signaled. The organism tends, moves, recoils; the symbol is merely a counter.

\section{THE HIATUS, PAR EXCELLENCE}

But some individuals are more gifted in acting than others. In the construction of meaningful actions some individuals are more capable of using symbols, motives, norms, and roles. But no one is "used by". symbols, motives, norms, etc.; no one is "taken by the role of the other." Meaning is contingent on the individual's ability to act, but there is no guarantee how effective in any situation the individual is going to be. There is a hiatus between what words or situations call for, and reciprocating action. As Becker $(1962 \mathrm{~b}: 496)$ illustrates, "The simple act of engaging someone by offering him a seat is fraught with possibilities of bungling." And this "bungling" is a matter of no small significance.

The hiatus, par excellence, between words and actions is schizophronia. The problom of schizophronia, as Bockor (1964b:52) arguos is that "words are not fused to organismic meanings." The problem, above al1, is ineptitude in acting, in initiating a response toward symbolic objects. While this is a very complex problem the general features of

*Dennis Wrong's (1970:38) advice might be germane here: "I think we must start with the recognition that in the beginning there is the body." 
schizophrenia is that "there seems to exist a real possibility of a split between mere apprehension and true experience of meaning" (Becker, 1964b:52). It is in this sense that the schizophrenic may ba aware of symbolic objects, "but no corresponding firm and broad range of interpersonal behaviors" (Becker, 1964b:132). Thus the schizophrenic is characterized frequently as possessing a complex and even infriguing "vocabulary" as to his experience, but an ineptitude in behaviofalty transacting with others or the object-world.

Furthermpre, theorists do not know at this time how compefence if acting becomes engendered in people. As Becker (1964b:20) says, "We have only the vaguest, most general notions on how experience is bufft into the organism." We do know that, with children, maternat fove nnd a corresponding "feeling" of high sense of worth is centrat for the child to begin behaviorally to panipulate his objectrwopld. But the long, behavioral transftion from childhood to adulthopd is complex anh, yet, equally important in terms of the development of a competent human. In terms of schizophrenia, the hiatus between words and actions has been depicted by laing as a person being "embodied," af "unempodied!"! The embodied person, says Laing (1960:67-70),

has a sense of being flesh and blood and bones, of being biologically alive and real; he knows himself to be substantial. To the extent that he is thoroughly "in" his body, he is likely to. have a sense of personal continuity in time,

The schizophrenic, on the other hand, does not experience his body as the center of his own causality. His responses to situations are confused, disjointed. Laing therefore characterizes this hiatus between words and actions as the individual being "unembodied." As Becker (1964b:51) further explains: 
This may be a clue to one aspect of the puzzling phenomenon of "schizophrenic language." When words no longer refer to potential organismic action, or to any felt organismic involvement, they lose their quality as true language. Dewey's observation is apt: he calls this split between word sound and organismic quality a "shortcircuiting."

\section{THE HIATUS AS EVERYONE'S PROBLEM}

As Mead (1934:147) said, "There is, of course, a great deal in one's conversation with others that does not arouse in one's self the same response it arouses in others." Moreover, as Mead also indicated, there is a great deal in conversation with one's self that does not receive a response that was anticipated. Responses are always uncertain. There is a hiatus, then, that is an integral feature of human behavior itself. It lies between one's self and one's actions, or between what we expect ourselves to do, and what in fact we actually do. Thus in each social situation this discrepancy is always a latent possibility, Each situation can involve the potentiality of discrediting the prized image of the self. Thus Becker (1964b:69) argues,

If one act can undermine a self, and one social role fragment it, then it can have no duration except in fantasy. But let me stress that this applies not to the schizophrenic only. This is the anxiety of every social actor. "I am nothing if each situation can construct me anew."

Managing situational inconsistency and confusion, then, is an absolute necessity in maintaining "self" in social interaction. "Questions" arise in conduct frequently because individuals say or think one thing and yet do another. "Nature, on the other hand, seems blissfully unconcerned with. anything except keeping action moving forward, proceeding from one situation to the next" (Becker, 1964b:70). The sense of continuity and permanence of one's self therefore becomes largely a product of one's ability 
to rationalize the discrepancy. into an acceptable accord to others. Of, as Becker (1964b:70) says, "Thus every individual is obliged to create the cause-and-effect myth of his own past." And this, of coupse, introduces the significance of motive-rationalizations of the discrepancies in social interaction. Motives function to justify "questioned" behavior to significant others. They function to bridge the hiatus between what words or situations call for and what actually occurs. 


\section{CHAPTER VIII}

\section{MOTIVES AS DRAMATURGICAL PROBLEMS}

A motive, as we have seen, is a justificatory reason in interactional contexts where behavior is being judged by significant others. It refers to a directed disposition toward a goal relative to one's orientation in a situation that explains the reason for the action. As such, motives introduce the problem of "drama" into human conduct, or the attempt by individuals to dramatize, through justification, their purposes and intentions. The critical variable of these dramatic appeals is, of course, the social audience from where questions toward one's behavior are first initiated. As Burke (1954:274) said:

Human conduct, being in the realm of action and end (as contrasted with the physicist's realm of motion and position) is most directly discussable in dramatistic terms. By "dramatistic" terms are meant those that begin in theories of action rather than in theories of knowledge (emphasis in the original).

Action is therefore the key variable underlying the construction of social meaning; meaning is not understood as a symbolic construct, a body of knowledge, or definitions that determine, in some sense, the significance of actions. As a theory of action, then, motives refer to dramatic appeals to significant others for justification of one's actions. Motives are therefore types of actions themselves. In this sense, motives, as dramaturgical actions, can be categorized into two types: discursive and apparent. "Discursive motives are those which are transmitted verbally, and apparent motives are those which are communicated by the appearance of the parties involved" (Edgley, 1971a:10). Obviously, 
one can justify one's conduct frequently through appearance only by, as in the case of a policeman, simply showing a badge or a seafch warrant. Even "appearing" within particular settings or situations can convey one's motives (see Stone, 1970 and Lyman and Scott, 1967). The mere presentation of self can convey motives, but yet, if further questioning is involved, one can resort to verbal justifications. The point is that one can not only give motives, but also give off motives (see Goffman, 1959).

This is not to suggest, however, that dramatistic appeals automatically work. Unsympathetic audiences, as Goffman (1959:51) critically notes, have a frequent "tendency to pounce on trifling flaws as a sign than the whole show is false..." The significance or meaning of motives is also contingent on the problematic responses of others. Untoward or questionable behavior can be "normalized" through motive avowa1, or the motive can be rejected and the audience thereby react toward the individual in unanticipated ways. ${ }^{12}$ Yarrow and Schwartz, et a1. (1955) have even studied the phenomenon of untoward behavior becoming normalized, not through motive-avowal, but through blunt denial on the part of the audience that anything unusual is happening. Audiences can clearly be either sympathetic, apathetic, or without mercy. Following this same logic, the question of whether a motive is "real" or not can therefore be determined on the basis of whether the motive is accepted or tolerated by the audience (Edgley, 1971b). "Unreal" motives are simply those that the audience will not accept. 13 


\section{STIGMA AS EVERYONE'S PROBLEM}

Understanding that the response of the audience is the contingent variable that determines whether a motive is accepted as "real" or not introduces the whole realization that being discredited and stigmatized is everyone's problem in all situations. As Howard Becker (1963:9) argues, meaning is not inherent in any particular behavior such as, say, a deviant act, but is "rather a consequence of the application by others of rules and sanctions to an 'offender'." The meaning of a given person's behavior, even if justified by an avowed motive, is determined by the consequence of the response of others. Thus, in all situations there is the latent possibility that inadvertent acts and discrepancies made by the individual can be used by an audience to discredit him. And, as Goffman (1959:51) describes, "even sympathetic audiences can be momentarily disturbed, shocked, and weakened in their faith by the discovery of a picayune discrepancy in the impressions presented to them." Moreover, as Goffman (1963:127) further indicates:

The most fortunate of normals is likely to have his half-hidden failing, and for every little failing there is a social occasion when it will loom large, creating a shameful gap between virtual and actual social identity. Therefore the occasionally precarious and the constantly precarious form a single continuum, their situation in life analyzable by the same framework.

Stigma, therefore, should be understood as a general feature of all societal situations. "The normal and the stigmatized are not persons but rather perspectives. These are generated in social situations during mixed contacts by virtue of the unrealized norms that are likely to play upon the encounter" (Goffman, 1963:138).14 


\section{MOTIVES AS PROBLEMS INVOLVING CONSEQUENNCES}

Motives do not involve, nor do they infer "causes" or "determinants" of actions. Rather, their social significance involves consequences, or how particular acts, including motive-avowals, are responded to by others. This underlies the problem of "meaning" in general. Meaning is on-goingly a problem of the future. Thus in terms of the meaning of motive-justifications, it is not, as Brissett (1971:12) argues, "as much a matter of something believed to be true being true in its consequences (a traditional notion in symbolic interactionism); rather, that something believed to be true is true only in its consequences" (emphasis in the original).

Within the dramaturgical theory of action (as motives have been shown to be a part), "cause" is a moot and silent problem. If the problem of "cause" is addressed at all, theorists simply say that any given action involves an endless variety of social, cultural, psychological, and physiological variables (see Lemert, 1967). As such, if one wants causally to explain action, theories of imitation, conditioned-response, instincts, or drives, etc.--all of these theories may have relevance, but they only amount to relatively arbitrary and partial explanations at best.

It can be said, therefore, that the significance of motivejustifications falls within an indeterminate theory of action. The emphasis is on the problematics of action, its volatability and change. ${ }^{15}$ Thus, as Strauss $(1959: 43)$ argues, "it is not change that needs to be explained but its specific directions; and it is not lack of change that needs to be taken into account, but change itself." In this respect the 
concept of "emergence" is germane (see p. 42). But the ability, "after the fact" on the basis of replication, fo naturalistically or deterministically explain the episode is largely rejected. First, all of the conditions--physiological, psychological, sociological, cultural--can never be completely specified. Moreover, replication is simply a problem of redescriptive rationalization. Thus its explanation is merely tautological. Lastly, replication as rationalization simply returns us to the problem at hand, the function in human action of rationalization in general. But the significance of rationalization is not a problem of involving the "real" explanation; the significance is whether it is accepted by others. Its critical importance is therefore centered around the problem of consequences. Or, how does a given social audience respond to an avowed motive or explanation, and for what reasons does a given audience accept one rationalization over another? As was discussed earlier, individuals can utilize and avow an innumerable number of relatively arbitrary motive-rationalizations or explanations to justify behavior in varying social contexts. Furthermore, the substance of an avowed rationalization or explanation is not, in and of itself, the important consideration, but the impact and influence the rationalization will have on the given audience. In this respect an individual can attempt to provide a rationalization for behavior that best satisfies the needs, interests, and assumptions of the social audience, and thereby maximize the probability of his success in negotiating the outcome of the social interaction. The key is the ability to match up an avowed rationalization with the expectations of the audience. Or, as Lyman and Scott (1970:125) have offered:

In interacting with others, the socialized person learns a repertoire of background expectancies that are appropriate for a 
variety of others. Hence the "normal" individual will change his account [or rationalization] for different role others. . . Both the account offered by ego and the honoring or non-honoring of the account on the part of alter will ultimately depend on the background expectancies of the interactants. By background expectancies we refer to those sets of taken-for-granted ideas that permit the interactants to interpret remarks as accounts in the first place (emphasis in the original).

Actually, the term "background expectancies" is a "catch-all" term for a complex assortment of different kinds of criteria that audiences utilize to judge the worth of a motive-avowal, depending on the situation. For instance, a patient in psychoanalysis will typically explain or rationalize his behavior in a particular vocabulary involving certain assumptions that are common to him, yet unacceptable to the psychoana1yst. This does not mean, however, that the patient's account is erroneous, for indeed in another circumstance it may be quite acceptable. But in this particular circumstance it is not unusual for a therapist to insist that the patient redress his account in a vocabulary and set of assumptions that compliments the authoritarian status and ideology of the professional. In fact, some argue that therapy can not progress in psychoanalysis until the patient reformulates his account into the vocabulary of the doctor (cf. Burke, 1954). In a particular situation, then, the significant background expectancies may involve only ideological or philosophic assumptions. In other situations they may involve considerably more.

Whether an account is honored or not may rest not on the criteria of philosophic assumptions, but more basic factors such as the political, social, and economic interests of the audience. For instance, many a conscientious objector has endured either long jail sentences or permanent exile not because their motives were necessarily insincere, but 
because the State interpreted their noncompliance as efther due to "other" motives or that their behavior represented a threat to the State's privilege and authority to induct men into military service, Another highly different example is the phenomenon of "symbolic crusades" where a larger party, due to a perceived threat to its status and prestige (as well as economic and political interests) sponsors the idea that another less powerful group harbors evil or dangerous motives against them and should therefore be treated either punitively or as an enemy (Gusfield, 1963). These examples, and of course many others, stand to illustrate that in the negotiation of motive-rationalizations, the interaction should not only be understood as a "drama" of one party appealing or accusing another party, but indeed, a political drama where the legitimacy of one individual's plea is judged by other's in terms of the latter's own interests of status, power, and ideology. These are some of the important factors that are involved in the broad notion of "background expectancies."

\section{THE SOCIOLOGY OF MOTIVATION}

The analysis of motivation, as found implicitly in Mead and explicitly in Burke, is only amenable to a sociological theory in so far as that theory maintains a consistent stance toward the nature of social meaning. Specifically, meaning can not be reified into impersonal objects that in some way determine the flow of behavior. Rather, meaning must be seen as on-goingly established by behavior and reciprocating responses. The significance of motives becomes relevant at this point because they function to justify behavior that is frequently meaningless and ambiguous. Indeed, it seems hard to imagine the relevance of motives at all if social 
meaning was constant and all-pervasive as depicted in traditional sociological metaphors. (Possibly this is why most traditional symbolic interactionists have had little to say about motives.)

In this sense, a sociological understanding of motives amounts to only one aspect of a larger theory of social action, namely dramaturgy. The entire emphasis of dramaturgy is to describe the intracacies and. processes through which meaning becomes established. Thus it repels theories of human behavior that explain action in terms of metaphors that largely exclude the significance of human behavior itself. Dramaturgists share Blumer's $(1969: 66)$ understanding "that human interaction is a positive shaping process in its own right. The participants in it have to build up their respective Iines of conduct by constant interpretation of each other's ongoing lines of action." The problem of motives becomes germane here because meaning is problematic and action frequentfy needs some form of justification.

In general, the significance of a sociological theory of motivation belongs to a larger theory of action that resists interpreting bahaviop on the basis of anything other than behavior itself, specifically, the relevance of motives lies in observing and describing the way in which people interpret their own behavior, and thus keep action moving. The analytic emphasis is to understand how people themselves on-goingly establish and Justify their reality; not in substituting through metaphor the meaning of action into another justificatory explanation or rationalization. This is simply to say that a sociology of motivation is not relevant to any "perspectives by incongruity." We need to understand how people interpret their own behavior, not how remote theorists can interpret it through an infinite number of metaphors. 
A sociology of motivation as outlined herein involves an appreciation of man as an artisan of his own art, an actor of his own dramas. Motives are dramatic appeals to audiences, and their significance involves consequences of other's actions toward self. Theoretically, what is needed therefore is a cogent description of human doings, a description of the forms and styles of actual human interaction. But the endless redescription of human actions on the basis of metaphor or tautology simply makes it less "real" and insightful. A description of human interaction considered dramatistically involves very much the same technique as that of the art critic in general:

The aim of all commentary on art now should be to make works of art--and, by analogy, our own experience--more, rather than less, real to us. The function of criticism should be to show how it is what it is, even that it is what it is, rather than to show what it means (Sontag, 1961:23) (emphasis in the original).

Men interpret their own actions, and build their own situations accordingly. A truly servicable science would therefore attempt to put men back in the role of being critics unto themselves. By doing so, a science would emphasize how man on-goingly constructs his world, and thus not how he is constructed by it. The task is to assist man in hearing, seeing, and feeling more of the consequences of his own actions. Or, as Sontag (1961:23) argues, "What is important now is to recover our senses. We must learn to see more, to hear more, and to feel more" (emphasis in the original). 
CHAPTER IX

CONCLUSION

The image of man conveyed by Mead's social behaviorism is that he is an active creature by nature. As Desmonde (1970:57) argues:

Mead also rejected the notion that [human] organisms passively. respond to stimuli. He contended that the organism dynamically selected its stimuli; it does not react to perception. The organism to a great extent determines its environment. . . . Mead thus [regarded] the organism as a dynamic, forceful agent molding the world around it, rather than existing as a mute receptacle for stimuli which are later associated.

In this same respect it has been argued that action is not the result of roles, norms, selves, or motives. Rather, men use roles, norms, and motives as aids in building up our own actions. Motives in particular are rationalizations the men use to justify the discrepancies in situated actions.

This understanding lends crucial insight even into the nature of larger organizations and structures. Men use organizations and develop a complex "under-life" to the structure itself, as Goffman (1961) has described so well. Similarly, even "lower participants" in complex organization creatively develop positions or power and status that incredibly determines the structure and functioning of the organization (see Mechanic, 1968). Moreover, modern organization and system theorists are becoming cognizant of the need for a more viable social psychology. As Buckley (1967:145) argues, as a more dynamic social psychology is embraced, "organizational behavior takes on a processual character of creation and recreation of meanings and expectations in a succession of 
situations that are only partially or not at all regularized and standardized." Buckley (1967:105) therefore argues that modern system theorists

represent an attempt at a rather complete overhaul of contemporary consensus theory by a return to social psychological basics and a rebuilding, from the ground up, of a balanced and dymamic conception of complex social organization.

Put simply, a viable system model must contain a viapla spcial psychptogy, and each dimension of the model must be congruent with ing apphif as well as ultimately being externally valid,

The illustrious metaphors of traditionat sociology and spctat psychology--social structures, organizations, statuses, roles, namp, selves--these metaphors have imbuded us with a conception of spctef thtep" action as being inherently ordered and sensible. But the mare one 1 s? able to break through these conceptual illusions, the more one is able fo see great discrepancy and confusion, not only in action, but in soctol prganization. The "social order" that we have been so used to affirming is therefore more progressively seen as a product of gur own rationalightion and justificatory powers. However, there is a discrepancy between our words and our actions. But pntil one begins accurafely to descflbp action, one will never know the present state of order of disprder if society. It has been argued that conceptualizing human action and motiva. tion as dramaturgical problems affords the basis of this kind of opjtical description. 


\section{NOTES}

1. Herbert Blumer (1969) was the first to label Mead's social behaviorism as "symbolic interactionism."

2. Psychologists have so thoroughly confused the notions of cause and motive that possible distinction between the two is probably not even within the realm of possibilities in that discipline: see, for example, R. W. White (1959) and a recent book considered a landmark in psychology by Cofer and Appley (1964).

3. It should be emphasized at this point that the terms "action," "meaningful action," and "behavior" are at times used interchangeably. However, all of these terms are meant to imply or refer to the construction of meaning in interactional terms; $i . e .$, the problem of individual actors fitting together and building up their lines of action co-jointly. Moreover, this qualification extends to include those references to the analysis of the actions of an individual actor; i.e., the dialogue between the "I" and the "Me" must be understood as a problem of interaction. A further explication of these assertions is given in Chapter One, sub-section "Action."

4. It should be parenthetically acknowledged that the interpretation in this essay of Mead's analysis of meaning is only one of several varying interpretations. The variance is largely due, I would argue, to an inherent circularity in Mead's analysis in that, depending on where the emphasis lies, meaning can be interpreted as either a shared, symbolic phenomenon between groups of individuals, or an interactional phenomenon that is on-goingly created and built up in behavior.

For instance, two extreme kinds of interpretations will be demonstrated. If meaning is established only when the response elicited by the symbol is the same for the one that elicits the symbols as well as for the one who acknowledges it, then the interpretation logically leans toward an understanding of meaning as being a symbolically shared, cognitive phenomenon between people. In this respect theorists then envision the human organism as becoming "funded" with socially shared meanings through such processes as socialization, education, inculcation of culture, and acquisition of language. It also lends an analysis to the problem of "universality," which Mead (1934:99) explained as

gestures or symbols that have the same or common meanings for all members of the group, whether they make them or address them to other individuals, or whether they overtly respond to them as made or addressed to them by other individuals. 
On the other hand, if meaning is established only when the response elicited by the symbol is the same for the one that elicits the symbol as well as for the one who acknowledges it, then the interprem tation of meaning shifts from a symbolic; cognitive phenomenon to a behavioral, interactional phenomenon that is on-goingly sustained by the nature of responses toward objects and other individuals. Far from becoming "universal," meaning becomes interpreted as a situational creation that is fundamentally problematic and achieved only on the basis of on-going interaction. Also, this interpretation is not to be understood as excluding or negating the possible role of consciousness and awareness with respect to the nature of meaning. Rather, instead of assuming, as does the former interpretation; that. interaction is continuously governed by rational and cognitive processes "in" the respective actors, the thrust of the second interpretation is that men can become conscious and are capable of rationalizing their actions. In this sense it is assumed that, "Only when . . activity is interrupted does man become conscious of himself and then in a rationalizing manner" (Brissett, 1971:12).

As the section on Mead already indicates, this essay emphasizes the latter interpretation of the nature of meaning although it does acknowledge that other interpretations offer theoretical utility, depending on the theorist's purposes. However, it is argued above that, with respect to the problem of motivation, the former interpretation typically involves assumptions about human behavior that are grossly over-socialized and mechanistic. It is around these issues, in fact, that a critique of the former interpretation of meaning is formulated. A reconceptualization of the problem of motivation is then offered based on the interpretation that meaning is an on-going creation of the activities of social interactants.

5. There is a very interesting contradiction here. Kuhn (1967:47) first notes that the oral tradition emphasized a "strain" to 'get it right', that is, to be correct." Yet later he argues that one can interpret Mead loosely because of the "elusive" nature of the oral tradition. Kuhn (1967:48) argues that numerous sub-theories stem from the essential ambiguities of Mead's position,

ambiguities and contradictions which were generally interpreted to be dark, inscrutable complexities too difficult to understand as long as the orientation remained largely in the oral tradition.

6. By "indeterminance," Kuhn (1967) is referring to theories that avoid explanations of human action in terms of antecedent and consequent variables. Indeterminate theories are fundamentally descriptive in nature. They analyze the way in which interactants attempt to fit their respective lines of action together, and thereby build up and sustain meaning in situations. The theorist thus avoids the tendency. to imagine, in some way, specific variables that determine meaning in situations. All references to indeterminate theories in this essay will follow Kuhn's distinctions. 
7. See especially Mills' (1962b:426-31) formulation of Mead's symbolic interactionism that represents a highly deterministic model of role theory especially designed for a sociology of knowledge.

8. It can be further argued that this use of tautological explanation by traditional symbolic interactionists, as well as sociologists in general, is the underlying source of sociological "reification." Berger and Luckman (1966:89) explain:

Reification is the apprehension of human phenomena as if they were things, that is, non-human or possibly supra-human terms. Another way of saying this is that reification is the apprehension of the products of human activity as if they were something else than human products . . (emphasis in the original).

Dramaturgists clearly see that the meaning of man's social world is ongoingly constructed on the basis of his actions toward social objects. But most symbolic interactionism and sociology explain behavior as a result of the meaning of these social objects. Thus "definitions of the situation," "roles," "norms," "reference groups," etc., become reified social objects that are used to explain resultant behaviors. Reification is therefore a product of tautology: on-going behavior, which is used as evidence of something like norms, roles, becomes conceptualized into an object which is then used to explain the original behavior. This has indeed been the traditional, theoretical fate of motives. As products of tautology, motives were seen to be not only indicated by behavior, but were also used causally to explain it. Thus, in considering the significance of motives, norms, and roles, if the theorist fails to stay close to Mead's understanding that meaning is an on-going product of behavioral response, his explanation is doomed to mysticism on the basis of tautology and reification.

9. Stone (1970:396) also sees the significance of Foote's paper as a supplement to role theory by providing an explanation of how one determines one's roles.

10. A similar "Grand Theory of Motivation" in sociology is advocated by Zetterberg (1957).

11. Meltzer's short analysis of the problem of motivation in Mead commits the same tautology as Foote. Meltzer (1967:18) says,

In my judgement, a conception of motivation can be formulated that is both useful and consistent with Mead's theories. Motivation can refer to "a process of defining (symbolically, of course) the goal of an act". . . . I mean to designate "motive," however, the definition the individual makes, at any given time, of the objectives of his own specific acts.

Here, again, the definition of an act is hypostatized into something different from the response itself. The act is based on the meaning or definition that precedes the response. Yet, this is a tautology because the meaning of a prior situation is given by the response to it. The meaning one imputes toward objects is not prior to the 
response, but is given in the response. Making the meaning into something different is redescription and redundancy.

12. For a discussion of the intricacies of normalization pracesses see Davis (1967) and Roman and Trice (1971).

13. This behavioral determination of whether a motive is "real" or "unreal" has obvious advantage over Gerth and Mills' somewhat mystical approach. They suggest that:

We may assume that the more deeply internalized in the person, and the more clearly integrated with the psychic structure, a vacabulary of motive is, the greater is the chance that it contains "the real motives." In fact, that is what "real motives" may be assumed to mean. We must, in order to "test" motives, therefore, attempt to find out on what level of character structure a given vocabulary is integrated (Gerth and Mills, 1953: 120).

How such a test may be carried out is never explained by Gerth and Mills. As indicated in the chapter on Mills, however, this somewhat mystical explanation of "real" motives is due to their misconception of meaning. Behavior does not result from the meaning of motives, the latter being conceptualized hypostatically as some kind of mentalistic phenomenon, such as an "attitude," or "thought," or as a "norm," or "situation." The meaning of a motive is behaviorally derived, or given by the response to it. It is only on the basis of this same logic that a determination of whether a motive is "real" or not can be made; i.e., on the response of the audience of either accepting the motive or rejecting it.

14. This situational understanding of stigma or deviance should therefore largely repudiate the tendencies of some theorists to make deviance a problem relative to only the codified laws of society (see Gibbons and Jones, 1971). Clearly, deviance involves the discrepancies in any situated action where self and others are judged.

15. It has also been argued that the indeterminant theory of action involved in a dramaturgical understanding of motives is "mystical" because it is said to imply notions of free will (see Bolton, 1971). This charge comes about largely by misconstruing the philosophy that underlies the dramaturgical theory of action and the sociology of dramaturgy. While Lyman and Scott (1970) correctly explain that dranaturgy has philosophic roots in modern existentialism that involves an emphasis on "freedom," this is merely a tangential point that is not built in to the sociology of dramaturgy itself. Specifically the meaning of action is never explained to be problematic due to the inherent "free will" of the individual, or that "free will" causes action to be problematic. Rather, the meaning of action is explained to be problematic in terms of an empirically grounded behaviorism. Put simply, action is said to be problematic because responses from others and one's self are not mechanically given but highly variable. The problematics of action is therefore given a strict sociological basis in dramaturgy. Since Mead, 
responses have been understood as being uncertain. "Why" this is so is a moot point. in dramaturgy. But it is never said that it is because of "free will."

16. This understanding leads a defense to dramaturgy toward the criticism by radical sociologists, namely Lichtman $(1970 ; 1971)$ and Horton (1971) that, by emphasizing the phenomenological aspects of reality as an on-going accomplishment, dramaturgy only amounts to a "do-ityourself, apolitical stance which can only affirm (apologize) by endlessly describing the reified construction of bourgeois reality" (Horton, 1971:189). For instance, radicals argue that

It is not enough to know that the objective appearance of reality is managed; we want to know also why that objectivity is so oppressive and how it can be overcome (Horton, 1971:188).

Thus Horton (1971:188) argues

The [dramaturgical] phenomenological method, while it contributes to a theoretical understanding of reification, is clearly not a method for radical dereification, because it cannot result in practical action against the reified social world.

Horton is arguing that dramaturgy can not result in "Praxis," which is a social-psychology involved in the Marxian concept of "dialectical thinking." Dialectical thought, which underlies Praxis, is explained by Schroyer (1971:132) as

By first expressing what a totality holds itself to be, and then confronting it with what it is, a [dialectical] theory is able to break down the rigidity of the object.

On the basis of dialectical thought, therefore, it is argued that Praxis becomes possible; men can not only see what "is" but what also "should be."

The dramaturgical retort is that, in order to see what is, one can no longer be concerned with the question "why?" This is simply because the problem leads to infinite regression, and almost always ends in tautology. Tautology, by the way, is Marxist's and radical sociologists' most common intellectual error. They are the most guilty of explaining the meaning of behavior on the basis of "productive forces," and "productive relations" which are both tautological reifications of action itself (see, for example, Marx, 1961).

Dramaturgists would argue that to see what "is," which is the basis of dialectical thought and Praxis, one must discontinue the endless tendency to explain human actions on the basis of tautological interpretations of behavior itself. Tautology merely reinforces a misinterpretation of what "is." The need, therefore, is for cogent description of action in its own terms. Only in this way can the first moment of the dialectic, what "is," be comprehended. And the meaning of what "is,". is what the actions of individuals on-goingly 
create, which is meaning. People have to be shown the creation of their own powers and actions. 


\section{REFERENCES}

Backman, Carl W. and Paul F. Secord.

1961 "Personality theory and the problem of stability and change in individual behavior," Psychological Review 68 (July):21-32.

1965 "An interpersonal approach to personality," in B. Maher (ed.), Progress in Experimental Personality Research. New York: Academic Press.

1968 "The self and role selection," in Chad Gordon and Kenneth J. Gergan (eds.), The Self in Social Interaction. New York: John Wiley and Son, Inc.

Baldwin, James Mark.

1968 "The self-conscious person," in Chad Gordon and Kenneth J. Gergen (eds.), The Self in Social Interaction. John Wiley and Son, Inc.

Berger, Peter and Thomas Luckman.

- 1966 The Social Construction of Reality. Garden City, New Jersey: Doubleday and Co., Inc.

Becker, Ernest.

1962a Birth and Death of Meaning. New York: Free Press of Glencoe.

1962b "Socialization, command performance, and mental illness," American Journal of Sociology 67 (March):494-501.

$1964 a$ 'Mills' social psychology and the great historical convergence on the problem of alienation," in Irving Louis Horowitz (ed.), The New Sociology. New York: Oxford University Press.

1964b The Revolution in Psychiatry. London: The Free Press of Glencoe.

Becker, Howard.

1963 Outsiders: Studies in the Sociology of Deviance. New York: The Free Press.

Blumer, Herbert.

1967 "Sociological analysis and the "variable'," in Jerome G. Manis and Bernard N. Meltzer (eds.), Symbolic Interaction: Boston: Allyn and Bacon.

1969 Symbolic Interactionism. Englewood Cliffs, New Jersey: PrenticeHall, Inc. 
1971 "The Significance of the 'Social Situation'," Presidential Address, Pacific Sociological Association Convention, Portland, Oregon.

Bolton, Charles D.

1963 "Is sociology a behavioral science?" Pacific Sociological Review 6 (Spring):3-9.

1971 "Some critical notes on the dramaturgical model." Portland State University, unpublished paper.

Brissett, Dennis.

1971. "The dramaturgical model: a reader in social psychology." Portland State University, unpublished paper.

Buckley, Walter.

1967 Sociology and Modern Systems Theory. Englewood Cliffs, New Jersey: Prentice-Hall.

Burke, Kenneth.

1954 Permanence and Change. Indianapolis: The Bobbs-Merril.1 Co., Inc.

Cassier, Ernest.

1953 - The Philosophy of Symbolic Forms. New Haven: Yale University 1955 Press.

Cofer, C. N. and M. H. Appley.

1964 Motivation: Theory and Research. New York: John Wiley and Sons, Inc.

Davis, Fred.

1967 "Deviance disavowal: the management of strained interaction by the visibly handicapped," in Jerome G. Manis and Bernard N. Meltzer (eds.), Symbolic Interaction. Boston: Allyn and Bacon.

Desmonde, William $\mathrm{H}$.

1970 "The position of George Herbert Mead," in Gregory P. Stone and Harvey A. Farberman (eds.), Social Psychology through Symbolic Interaction. Waltham, Massachusetts: Xerox College Publishing.

Dewey, John.

1930 Human Nature and Conduct: An Introduction to Social Psychology. New York: The Modern Library.

Douglas, Jack D.

1967 The Social Meanings of Suicide. Princeton, New Jersey: Princeton University Press.

Edgley, Charles Kenneth.

1971 a "Introduction to the dramaturgical theory of motives." State University of New York at Buffalo, unpublished paper. 
1971b Vocabularies of motive and the social definition of schizophrenia: an exploratory study. State University of New York at Buffalo, unpublished Ph.D. dissertation.

Foote, Nelson

1967 "Identification as the basis of a theory of motivation," in Jerome G. Manis and Bernard N. Meltzer (eds.), Symbolic Interaction. Boston: Allyn and Bacon.

Gerth, Hans and C. Wright Mills.

1953 Character and Social Structure. New York: Harcourt, Brace and World, Inc.

Gibbons, Don C. and Joseph Jones.

1971 "Current definitions of deviance," Pacific Sociological Review 14 (January) :20-37.

Goffman, Erving.

1959 Presentation of Self in Everyday Life. Garden City, New York: Doubleday Anchor.

1961 "The underlife of a public institution: a study of ways of making out in a mental hospital," Asylums: Garden City, New York: Doubleday and Co., Inc.

1963 Stigma. Englewood Cliffs, New Jersey: Prentice-Hall.

Gusfield, Joseph R.

1963 Symbolic Crusades. Urbana: University of Illinois Press.

Horton, John.

1971 "The fetishism of sociology," in J. David Colfax and Jack L. Roach (eds.), Radical Sociology. New York: Basic Books; Inc.

James, William.

1968 "The self," in Chad Gordon and Kenneth J. Gergen (eds.), The Self in Social Interaction. New York: John Wiley and Sons, Inc.

Kuhn, Manford $H$.

1967 "Major trends in symbolic-interaction theory in the past twentyfive years," in Jerome G. Maris and Bernard N. Meltzer (eds.), Symbolic Interaction. Boston: Allyn and Bacon.

Laing, R. S.

1960 The Divided Self: A Study of Sanity and Madness. Chicago: Quadrangle Books.

Lemert, Edwin M.

1967 Human Deviance, Social Problems, and Social Control. Englewood Cliffs, New Jersey: Prentice-Hall. 
Lichtman, Richard.

I970 "Symbolic interactionism and Marxism," Berkeley Journal of Sociology 5 (Summer):1-15.

1971. "Social reality and consciousness," in J. David Colfax and Jack L. Roach (eds.), Radical Sociology. New York: Basic Books, Inc.

Louch, A. R.

1969 Explanation and Human Action. Berkeley: University of California Press.

Lyman, Stanford M. and Marvin B. Scott.

1967 "Territoriality: a neglected sociological dimension," Social Problems 15 (Fal1):236-248.

1970 A Sociology of the Absurd. New York: Appleton-Century-Crofts. Marx, Karl.

1961 "Germany ideology," in Erich Fromm (ed)., Marx's Concept of Man. New York: Frederick Ungar Publishing Co.

MacIver, Robert.

1940 "The imputation of motives," American Journal of Sociology 46 (July) :1-12.

Mead, George Herbert.

1934 Mind, Self and Society. Chicago: The University of Chicago Press.

1938 The Philosophy of the Act. Chicago: The University of Chicago Press.

Mechanic, David.

1968 "Sources of power of lower participants in complex organizations," Medical Sociology. New York: The Free Press.

Meltzer, Bernard N.

1967 "Mead's social psychology," in Jerome G. Manis and Bernard N. Meltzer (eds.), Symbolic Interaction. Boston: Allyn and Bacon.

Mil1s, C. Wright.

1959 The Sociological Imagination. New York: Oxford University Press.

$1962 a$ "Situated actions and vocabularies of motive," in Irving Louis Horowitz (ed.), Power, Politics, and People. New York: Ballantine Books.

1962b "Language, logic and culture," in Irving Louis Horowitz (ed.), Power, Politics and People. New York: Ballantine Books. 
Peters, R. S.

1958 The Concept of Motivation. New York: Humanities Press,

Roman, Paul M. and Harrison M. Trice.

1971 "Normalization: a neglected component to labeling theory." Unpublished paper presented in the section on Social Deviance, American Sociological Association Convention, Denver, August 31.

Sapir, Edward.

1921 Language: An Introduction to the Study of Speech. New York: Harcourt, Brace.

Schroyer, Trent.

1971 "A reconceptualization of critical theory," in J. David Colfax and Jack L. Roach (eds.), Radical Sociology. New York: Basic Books, Inc.

Schur, Edwin M.

1971. Labeling Deviant Behavior. New York: Harper and Row.

Shibutani, Tamotsu.

1967 "Reference groups as perspectives," in Jerome G. Manis and Bernard N. Mèltzer (eds.), Symbolic Interaction. Boston: Allyn and Bacon.

Sontag, Susan.

1961 Against Interpretation. New York: Dell Publishing Co.

Strauss, Anselm I.

1969 Mirrors and Masks: The Search for Identity. San Francisco, California: The Sociology Press.

Stone, Gregory P.

1970 "Appearance and the self," in Gregory P. Stone and Harvey A. Farberman (eds.), Social Psychology through Symbolic Interaction. Waltham, Massachusetts: Xerox College Publishing.

Swanson, Guy.

1967 "Mead and Freud: their relevance for social psychology," in Jerome G. Manis and Bernard N. Meltzer (eds.), Symbolic Interaction. Boston: Allyn and Bacon.

White, R. W.

1959 "Motivation reconsidered: the concept of competence," Psychological Review 66 (September):297-333.

Whorf, Benjamin I.

1956 Language, Thought, and Reality. Massachusetts: Technology Press of Massachusetts Institute of Technology.

Wrong, Dennis.

1970 "The oversocialized conception of man in modern sociology," in Gregory P. Stone and Harvey A. Farberman (eds.), Social 
Psychology through Symbolic Interaction. Waltham, Massachusetts: Xerox College Publishing.

Yarrow, Marian Radk, Charlotte Green Schwartz, Harriet S. Murphy, and Leila Calhoun Deary.

1955 "The psychological meaning of mental illness in the family," The Journal of Social Issues 21 (Spring):12-21.

Zetterberg, Hans L.

1957 "Compliant actions," Acta Sociologia 2 (Spring):186-193. 